\title{
Health Spillover Effects of a Conditional Cash Transfer Program*
}

\author{
Diana Contreras Suarez ${ }^{\dagger}$ and Pushkar Maitra ${ }^{\ddagger}$
}

September 2020

\begin{abstract}
Forthcoming: Journal of Population Economics
\end{abstract}
\begin{abstract}
We use data from the Familias en Acción program in Colombia to examine the spillover or indirect effects of a conditional cash transfer program. Our results show that the program has significant spillover effects: it leads to an improvement in the health of non-targeted individuals in treatment households in terms of both incidence and severity of illness. The benefits are stronger for women and the elderly in the short run and for men in the medium run. Our analysis suggest that these spillovers are driven by increased access to information in the household that creates a public good.
\end{abstract}

Key Words: Conditional Cash Transfer, Health Spillovers, Colombia, Familias en Acción, mechanisms

JEL Codes: O15, I15, I38, D62

${ }^{*}$ We would like to thank the editor, Shuaizhang Feng, and two anonymous referees of this journal, Sarah Baird, Paul Christian, Juan Miguel Gallego, Bansi Malde, Manuel Ramirez and seminar and conference participants at the Centre for Health Economics at Monash University, the Universidad del Rosario, the Australasian Econometric Society Meetings, the Australian Health Economic Society Meeting and the NEUDC Meetings for their comments and suggestions. The usual caveat applies.

${ }^{\dagger}$ Melbourne Institute: Applied Economics \& Social Research, The University of Melbourne, Level 5, FBE Building (111 Barry Street), Victoria 3010, Australia. Tel: +61 383443 567. Email: diana.contreras@unimelb.edu.au. ORCID iD: 0000-0003-0991-7029. Corresponding Author.

${ }^{\ddagger}$ Department of Economics, Monash University, Clayton Campus, VIC 3800, Australia. Email: Pushkar.Maitra@monash.edu. ORCID iD: 0000-0003-0247-4069. 


\section{Introduction}

Policy makers in developing countries around the world are increasingly using conditional cash transfers (henceforth CCTs) to improve the health, nutritional and educational outcomes of children in poor households. ${ }^{1}$ These schemes give stipends and food to the poorest if they meet specific conditions (for example, their children attend school or their babies are vaccinated). The main idea behind CCTs is to promote long-run development by targeting poor households with children and incentivizing care-givers to invest in their children's human capital. Healthier and better educated children are likely to be more productive adults and to have higher earnings, thereby breaking the vicious cycle that perpetuates poverty over generations. Indeed, The Economist has termed CCTs as the world's favourite new anti-poverty device (Economist, 2010).

In this paper we examine the indirect effects, or spillovers, associated with CCT programs. Direct effects of such programs have been extensively studied, and it is now generally accepted that CCT programs have significant effects on children. The positive direct effects are the result of these programs improving children's nutritional status (Behrman and Hoddinott, 2005, Attanasio and Mesnard, 2006), health status (Gertler and Boyce, 2001, Gertler, 2004, Attanasio et al., 2004, 2005), school participation (Baez and Camacho, 2011, Attanasio et al., 2005, Fitzsimons and Mesnard, 2008, Attanasio et al., 2010) and consumption (Maluccio and Flores, 2005, Attanasio et al., 2005). These are direct effects as the CCTs were indeed targeted to improve children's outcomes, particularly health. ${ }^{2}$

However, these programs can also have positive effects on members of the households who were not targeted directly by the programs. We call these indirect effects, or spillovers, of the program. In this case, effects on adults are spillovers of the program. ${ }^{3}$ This aspect of CCT programs has

\footnotetext{
${ }^{1}$ See Fiszbein and Schady (2009), DFID (2011), Baird et al. (2011), Bastagli et al. (2016) (among others) for more on CCT programs. Bastagli et al. (2016) report that 63 low and middle income countries around the world have some form of a conditional cash transfer program.

${ }^{2}$ See Lagarde et al. (2007) for a survey of the direct effects on health of CCT programs.

${ }^{3}$ We use the terms indirect effects and spillovers synonymously. Importantly, we define spillovers as different from unintended impacts. While unintended impacts are defined in the light of outcomes that were not targeted by the program design, spillovers are defined in terms of the effects on individuals who were not targeted in the program design. Adults in the household are not targeted in the program we consider, and the program's design does not include any incentive to improve the health of non-targeted adult members of the household.
} 
been considerably less studied but may be an important part of their overall effect. Ignoring indirect effects can result in significant underestimation of the aggregate effects of the program.

We use data from the Familias en Acción (henceforth FA) program in Colombia to examine indirect effects on the health of household members who were not the targeted beneficiaries of the program. The FA program has been in operation in Colombia since 2002. Its primary aim is to increase the level of human capital of children in the poorest households of the country. This is done by providing monetary transfers to the primary caregivers in beneficiary families, conditional on children (the targeted beneficiaries) satisfying specific health care and school attendance requirements. The requirements were that children under 6 should be taken to health centres for monthly health and development check-ups and that children ages 7-17 should regularly attend school.

Our focus is on the health and nutrition component of the program, which was targeted at households with at least one child ages $0-6$. Eligible households that satisfied the condition received a flat monthly monetary supplement of 46500 pesos. ${ }^{4}$ This amount was fixed, not dependent on the total number of eligible children in the household, and equal to $16-20 \%$ of the average monthly income of eligible households. The transfer was expected to work by supplementing children's food consumption. Attanasio et al. (2005) find that the program reduced the occurrence of diarrhoea by $33 \%$ for children less than 24 months old and by $51 \%$ for children ages $24-48$ month living in rural areas. Additionally, during the first year of their life, boys in treatment households grew 0.44 centimetres more than those in control households. The estimated direct effects are therefore significant. ${ }^{5}$

The primary caregiver of the child (called the titular) who accompanied the child to the health centre was required to attend information sessions on nutrition, hygiene and contraception. ${ }^{6}$ Adults other than the primary caregiver were not required to attend the health information sessions. Therefore, only the primary caregiver received useful advice about nutrition and the

\footnotetext{
${ }^{4}$ US $\$ 20.45$ at the 2002 exchange rate.

${ }^{5}$ In Table 8 of this paper, we also show that the program has a positive effect on the likelihood of stunting (child's height-for-age z-score $<-1$ ).

${ }^{6}$ Around $82 \%$ of the titulars were the mother of the child and $95 \%$ of the titulars were females.
} 
prevention of common diseases. Because adults other than the primary caregiver were not required to accompany their children to the health centres, there are no features of the program design (conditions or incentives) that should directly lead to improvements in the health of adult members of the household who were not the primary caregiver. Any observed treatment effect of the program on the health of these non-targeted adults is therefore an indirect effect, or spillover, of the program. ${ }^{7}$

Evidence on within-household spillovers of CCT programs is quite scarce. Some exceptions include Chaudhuri (2009) who, using data from Bangladesh, finds a significant positive spillover impact on the health of the never-targeted elderly women of a particular reproductive health program that targeted mothers and children in randomly selected treatment areas. Ver Ploeg (2009) finds that children who are age-ineligible for the Women, Infants and Children (WIC) program in the US but live in WIC-participating families have healthier diets than similar children in nonparticipating families. Bustelo (2012) examines the spillover effects associated with Nicaragua's Red de Proteccion Social CCT program and finds that, while the program specifically targets children ages $7-13$ who have not completed $4^{\text {th }}$ grade, there are positive schooling effects within the households for older, non-targeted siblings, with larger impacts for boys than girls. Kazianga et al. (2013) evaluate the impact of two different school feeding programs (school lunches and take home rations) on the health outcomes of pre-school children in Burkina Faso. They find that take home rations have a significant impact on the health of younger siblings within the household. younger children were not directly eligible, therefore any impact on their health could be viewed as a spillover attained through intra-household reallocation of food. Indeed, as in our case, Kazianga et al. (2013) argue that ignoring such spillovers under-estimates the overall effect of the intervention. ${ }^{8}$

\footnotetext{
${ }^{7}$ Contrast this with the PROGRESA program. As Gertler (2004) notes, the program imposes the explicit condition that other family members visit clinics once a year for physical checkups and that all adult family members participate in regular meetings at which health, hygiene, and nutrition issues and best practices are discussed (see Gertler, 2004, page 337). Thus one could argue that other adults in the household were also targeted beneficiaries of the program. That is not the case in the FA program.

${ }^{8}$ There is a larger literature on across-household spillovers of CCT programs that take the form of gifts or other transfers (Angelucci and De Giorgi, 2009), an increase in overall incomes (Angelucci and De Giorgi, 2009), learning from peer interaction (Bobonis and Finan, 2009, Lalive and Cattaneo, 2009), changes in behavior due to changes in social norms (Avitabile, 2011), or the desire to behave like the eligible population in the hope that they would become eligible, particularly when the eligibility criteria are not well defined within the community and knowledge spillovers occur (Bobba and Gignoux, 2019). There is also evidence that CCTs have significant effects on other
} 
We find that there are indeed strong within-household spillover effects. In the short run, the strongest effects are on the incidence of illness. Non-targeted adults in treatment households were significantly less likely to report being ill in the 15 days prior to the survey compared with adults in control households. The effects persist over a longer period of time and lead over time to better health and a reduction in the severity of illness, captured by lower rates of reported hospitalization. The effects are quite heterogeneous, benefiting women and the elderly in the short run and men in the medium run. Our analysis suggests that looking only at the direct effects (in this case, the health of targeted children) results in significant underestimation of the total effect of such CCT programs.

There can be a number of different pathways through which the within-household spillovers can arise: the cash transfer component of the FA program frees up resources for other members creating an income effect; the program produces a public good effect as health information can be accessed by all household members; and the program generates a positive contagion effect as a result of healthier children and more hygienic surroundings within the household that decreases the likelihood of disease transmission. ${ }^{9}$ The three components are mutually reinforcing, but from a policy point of view it is important to know which effect is the strongest. Our results suggest that the driving mechanism is household-level public goods, not a relaxation of the household budget constraint as a result of the cash transfer nor a contagion effect arising from improved health of the children in the household.

The rest of the paper is organized as follows. Section 2 describes the FA program in detail. Section 3 discusses the data, the associated descriptive statistics and the estimation methodology. Section 4 presents the results and Section 5 discusses the potential mechanisms. Finally, Section 6 concludes.

domains of life, for example, crime and conflict (Chioda et al., 2016, Crost et al., 2016).

${ }^{9}$ In Section A1 (in the Appendix), we present a simple theoretical framework to show how the three channels could manifest. This is, of course, not to say that these three channels are exhaustive. The program can lead to improvements in the supply of basic health services either as part of the program or as a part of a complementary strategy to expand health services in areas where the program is implemented. Alternatively, the program could provide preferential or facilitated access to services to the eligible. We do not consider these supply-side factors in this paper. 


\section{The Program}

The overall aim of the FA program is to increase the level of human capital of children in the poorest households (those in the first quintile of the income distribution), by providing monetary transfers to it titulars in beneficiary families, conditional on having completed specific requirements. The program was first targeted geographically. Of the approximately 900 municipalities in Colombia, 622 were chosen by Fondo de Inversiones para la Paz, as targets. The targeted municipalities were required to meet all of the following requirements: $(i)$ have less than 100,000 individuals, should not be the capital of a regional department and should not be in the coffee growing region that received special help following the 1995 earthquake; $(i i)$ have at least one bank; ( iii) have a minimum level of health and education infrastructure; and (iv) the local authorities must have complied with the administrative tasks necessary to participate in the program, which included providing a list of the SISBEN 1 beneficiaries. ${ }^{10}$ In the case of FA, only households belonging to SISBEN 1 and having children aged 0-17 as of December 1999 were eligible. These households constitute approximately the bottom twenty percent of Colombian households (see Velez et al., 1998). The program started, with some exceptions, in the second half of 2002 and the take up among eligible households was over 90 percent.

A quasi-experimental methodology was used to evaluate the program. The municipalities were grouped according to the number of eligible families living in each one, to form the Primary Sampling Unit (PSU). Typically, a PSU coincided with a municipality, though in some cases two or more small adjacent municipalities were combined to form a PSU. Among the targeted municipalities, the evaluation team selected 50 treatment PSUs, to form a stratified random sample. These 50 PSUs were matched with 50 control PSUs, that were not in the set of targeted PSUs but were reasonably similar to the targeted PSUs in terms of population size, index of quality of life and health and education infrastructure. The next step was to select a random sample of eligible households. Within each PSU, the evaluation team randomly selected 10 geographic

\footnotetext{
${ }^{10}$ The SISBEN is a proxy means test indicator of economic wellbeing that is used throughout Colombia to target welfare programs. Families were surveyed by the municipal authorities and centrally classified into one of the six categories according to their level of measured poverty. The poorest families were classified in level 1 , and the richest in level 6 .
} 
clusters and within each of these clusters 20 households were randomly selected from the set of SISBEN 1 households. Approximately 10 households per cluster were included in the final evaluation sample, which consisted of around 11500 households, residing in 122 (57 treatment and 65 control) municipalities. See IFS (2004) for more on the sampling and survey methodology. A household was eligible (for the health component of the program) if there was at least one child aged 0-6 in the household at the baseline. We define a household to be a treatment household if it is eligible and resides in a treatment municipality and a household to be a control household if it is eligible but resides in a control municipality. We are specifically interested in the effects of the program on individuals aged 18 or higher (at the baseline) who would not have been exposed to either the health or the education components of the FA program.

Given the quasi-experimental methodology adopted for the evaluation of the program, the treatment and control samples could end up being different along a number of different dimensions. Testing for similar pre-treatment trends helps supporting the comparability assumption between municipalities. We do not have information on adults' health status before the treatment and rely on the evidence provided by Attanasio et al. (2010) on parallel pre-trends in labour market outcomes for adults. ${ }^{11}$

\section{Data, Descriptive Statistics and Estimation Methodology}

\subsection{Data and Descriptive Statistics}

The data used in this paper come from panel data collected for the evaluation of the impact of the FA program. The data collection was done in three rounds. A baseline (in 2002) before the start of the program; a first follow up, conducted one year later (i.e., in 2003) with the primary aim of obtaining the short run impact of the program; and a second follow-up survey, conducted in 2006,

\footnotetext{
${ }^{11}$ In the main regression results we present the difference-in-difference estimates, controlling for baseline observables, bearing in mind that there is a potential for the estimates to be biased. To analyze the extent of this (potential) bias, we examine the robustness of the results using propensity score matching in the comparison of treatment and control households. These results are discussed in Section 4.4.4.
} 
with the aim of assessing the medium term impact of the program. ${ }^{12}$ At the baseline, a total of 7229 households with children aged $0-6$ were interviewed. The attrition rate was approximately 6 percent in the first follow up, with 6788 households being re-interviewed. The attrition rate was slightly higher for the treatment households (6.5 percent) compared to the control households (5.5 percent). The overall attrition rate is higher in the second follow up: 6100 households were re-interviewed, which translates to an attrition rate of 15.6 percent relative to the baseline. The attrition rate was similar for treatment and control households (15.6 percent and 16.4 percent, respectively).

Attrition, if non-random (particularly if the likelihood of attrition is correlated with the baseline variable of interest) could result in biased estimates. To examine the issue of attrition in more detail, in unreported regressions we first estimate a probit model where we regress attrition on a set of baseline observables and including a set of quality of fieldwork at the baseline as additional explanatory variables. ${ }^{13}$ The dependent variable in this regression is $\operatorname{ATTRITE} E_{s}$, a dummy variable that takes the value of 1 if the household is not surveyed in the first $(s=1)$ or the second $(s=2)$ follow up survey. While a number of observable (household, geographical and interview) characteristics significantly affect the likelihood of attrition, the Treatment dummy is not statistically significant, indicating that there is no evidence of differential attrition across the treatment and control households.

If the initial health status of individuals in attriting households is different from those in nonattriting households, our program effects will be biased. To examine this, we regress the two outcome variables of interest for the baseline sample, on the baseline observables, the attrition dummy (ATTRITE) and a set of interaction terms between the attrition dummy and each of the explanatory variables. The non-interacted coefficients give us the effects for the (eventually) nonattriting households while the interacted coefficients give us the difference between the attriters and non-attriters at the baseline. A test of the joint significance of the ATTRITE dummy and

\footnotetext{
${ }^{12}$ See http://www.dnp.gov.co for more details.

${ }^{13}$ We include the number of visits to complete the interview, the number of enumerators to complete the interview, the number of supervisors of the enumerators and if the interview was incomplete as measures of the quality of the interview. We also include dummies for the supervisor code and the percentage of attrition in the municipality. See Fitzgerald et al. (1998) for more on this methodology.
} 
the interaction terms tells us whether the attriting households are different from the non-attriting households. The results (not presented in the paper but available on request) show that the null hypothesis - that the attriting households are not different from the non-attriting households can never be rejected. There is therefore no evidence to suggest that attrition is non-random.

As the primary aim of the program was the child's health, the surveys were designed to evaluate the effectiveness of the program and did not include extensive measures of health of other (non targeted) members of the household. We are therefore restricted in terms of what variables we can use to measure health impacts of the program. We use the following two variables:

1. Self-reported illness in the last 15 days (was the individual ill during the 15 days prior to the survey?)

2. Was the individual hospitalized in the last year?

While it could be argued that the threshold of what is considered good health varies systematically across a society, controlling for their objective health status ${ }^{14}$, in the context of this paper, this is unlikely to be a major problem as all households in the sample (both in the treatment and control municipalities) are drawn from the poorest income quantile. The second measure (whether the individual had been hospitalized in the one year prior to the follow-up survey) is a longer-term measure of health and is based on an objective assessment by a health care professional. This variable is less likely to suffer from the cultural conditioning problem. Additionally, hospitalization could also be regarded as a measure of the severity of the illness.

Table 1 presents the differences between treatment and control at the baseline. Overall, we find that barring minor exceptions, control and treatment municipalities and households in control and treatment municipalities are generally similar in terms of observables. The average literacy rates in control municipalities are higher than that in treatment municipalities as is overall political engagement, captured by the number of mayoral candidates. In terms of household characteristics,

\footnotetext{
${ }^{14}$ For example, individuals who are more educated, wealthier and from socially advantaged groups, are typically more aware of the limitations imposed on them by their health status and are more likely to report themselves (and their family) as being of poor health. This is known as the cultural conditioning problem.
} 
the only variable that is statistically significantly different between the control and treatment households is whether or not the household has access to private health insurance (higher in control households).

In terms of health status at the baseline, individuals in the treatment households were worse off compared to individuals in control households: both the intensity and severity of illness is significantly higher for individuals in treatment households. The initial differences in the outcome variables are taken into account once we estimate a difference-in-difference program effect.

Finally, we do not find any evidence of differential mortality at the baseline between treatment and control households: p-value of difference in the likelihood of any member of the household dying in the last 12 months prior to the baseline survey is 0.462 .

\subsection{Estimation Methodology}

We use a difference-in-difference model to estimate the intent-to-treat (ITT) estimates of the program on non-targeted individuals in treatment households. The panel dimension of the data for the health outcome of interest allows us to control for initial differences across groups. Our primary estimating equation takes the following form:

$$
H_{i c t}=\beta_{0}+\beta_{1} \text { Treatment }_{c}+\beta_{2} \text { Year }_{t}+\beta_{3} \text { Program }_{c t}+\mathbf{X}_{i c}^{\prime} \gamma+\varepsilon_{i c t}
$$

Where $H_{i c t}$ is an outcome of interest (for example health of an adult in household $i$ residing in municipality $c$ at time $t$ ); Treatment $t_{c}$ is a dummy variable for the treatment group or community; Year $_{t}$ is an indicator variable for the post-intervention period; Program Pt $_{\text {in }}$ is andicator variable for assignment into the program (this variable takes the value of 1 for treatment municipalities in the post intervention period); $\mathbf{X}_{i c}$ is a set of baseline individual, household and municipality characteristics to control for any remaining pre-treatment differences and $\varepsilon_{i c t}$ is a random disturbance term. Standard errors are clustered at the municipality level. The causal estimate of assignment to the program on the health of non-targeted individuals in the household is given by 
$\beta_{3}$, which gives us the ITT estimates of the program. The sample is restricted to adults aged 18 and higher, residing in households with at least one child aged $0-6$ at the baseline.

\section{Results}

\subsection{Full Sample}

We start by presenting in Table 2 the overall program effects (captured by Program, see equation (1)). Column 1 presents the results for the program effects on the likelihood of being ill in the 15 days prior to the survey and column 2 the likelihood of being hospitalized in the year prior to the survey. Marginal effects from probit regression are presented. Panel A presents the short run effects (i.e., effects at the first follow-up), while Panel B presents the medium run effects (i.e., effects at the second follow-up). Recall that the estimating sample includes all adults aged 18 and higher in sample households in the treatment and control municipalities.

The regression results in column 1 of Table 2 show that in the short run, the program leads to a 2.82 percentage points decrease in the likelihood of reporting ill. This represents a $15 \%$ drop relative to the control mean at baseline. In the medium run, while the program effect remains fairly large in magnitude ( $11 \%$ relative to the baseline in control households), the effect is no longer statistically significant.

The program effects are different when we consider the impacts on long term health (captured by hospitalization rates). As the results presented in column 2 show, there is no short run effect but in the medium run the program has a statistically significant $25 \%$ reduction in the likelihood of being hospitalized in the year prior to the survey.

\subsection{Heterogeneity in Program Effects}

We next examine whether the program effects vary across different sub-samples. Specifically, we examine whether the program effects are different by age groups and by gender. In terms of 
age, we investigate the effects of the program on working age adults (individuals aged 18-59 at the baseline) and the elderly (individuals aged 60 and higher at the baseline) separately. We categorize individuals to different age groups based on their age at the baseline. Thus, individuals remain in the same age category across all survey rounds. These groups have different risk factors and their access to and use of new information might differ systematically. For example, the elderly are potentially more sensitive to infectious diseases and chronic conditions. On the other hand, the loss of productivity due to poor health is greater for working age adults and this can have significant long term impacts on economic growth and development. Similarly, how men and women access and use information and household income might differ considerably.

Table 3 presents the effects by age group: columns 1 and 2 those for the likelihood of reporting ill and columns 3 and 4 for the likelihood of being hospitalized. Again, Panel A presents the short run effects (at the first follow-up), while Panel B presents the medium run effects (at the second follow-up). As column 1 shows, for the working age adults (aged 18-59) there is no program effect on the likelihood of being ill, either in the short run or medium run. The program does however, in the medium run, lead to a statistically significant $22 \%$ reduction in the likelihood of a working age adult being hospitalized in the year prior to the survey (see column 3). There is however no short run effect.

The results for the elderly are quite different. The results in column 2 imply that in the short run the program is associated with a 8.6 percentage point (25\%) reduction in likelihood of reporting ill in the 15 days prior to the survey. In the medium run this effect is halved and is not statistically significant. As far as hospitalization is concerned, in the medium term, the elderly report being 4.8 percentage point (or $42 \%$ ) less likely to have been hospitalized in the year prior to the survey. The results are indicative of significant improvement in long term health, measured by a reduction in the intensity of illness, for both working age adults and the elderly. ${ }^{15}$

\footnotetext{
${ }^{15}$ We also examine whether the results are driven by heterogeneity of average health in the household at the baseline. We divide the sample into two groups: households that were in better health at the baseline and households that were in poorer health. We define better and poorer health accordingly to the average household health relative to the sample mean (proportion of household members reporting ill or reporting hospitalization); those with average $<$ mean for the sample (better health at baseline) and those with average $\geq$ mean for the sample (poorer health at baseline). The regression results for the two sub-samples are presented in Table A1: columns 1-4 for households with better health at baseline and columns 5-8 for households with poorer health at baseline. We include two different ways of classifying households: in Panel A according to the average health of adults aged 18-59 and Panel
} 
Next, we examine whether there are any gender effects of the program. The primary caregiver or the titular, the person who accompanies the child to the health centre and attends the conferences and workshops on health, hygiene and nutrition, is typically a woman (approximately 95\% of the primary caregivers are females). It is therefore worth examining whether the spillover effects are differentiated along gender lines. If, for example, women have more information on the behavior of other women and of children and can advise them, the peer effects could be stronger for women. On the other hand, if men are better able to internalize the information about health improvements or can reallocate more resources towards their own health, the effects could be stronger for men. ${ }^{16}$ Tables 4 and 5 present the gender specific regressions on reported illness in the 15 days prior to the survey and reported hospitalization in the year prior to the survey respectively; columns $1-3$ for women (separately for all women, working aged women and elderly women) and columns 4-6 for men (again separately for all men, working age men and elderly men). In both Tables, Panel A presents the short run impacts and Panel B the medium run impacts.

In the short run, women in treatment households are 3 percentage points (15\%) less likely to be ill compared to women in control households (Table 4, Panel A, column 1). The effect is smaller for men (at 2.7 percentage points) in treatment households (Panel A, column 4) and not statistically significant. The results in the medium run (Table 4 Panel B) are very different. Here there are no effects on the likelihood of a woman reporting being ill in the 15 days prior to the survey. On the other hand, men in treatment households are 3.4 percentage points (or 20\%) less likely than men in control households to report being ill in the corresponding period. The age specific effects show that the impacts are primarily driven by the large decrease in the likelihood of elderly men reporting being ill in the 15 days prior to the survey.

Turning to the results on hospitalization (Table 5), the short run effects for either gender and either age category is small and not statistically significant. On the other hand, the effects in the medium run are large and statistically significant. For both women and men in the working

B according to the average health of the elderly, 60 and higher. The results in Panel A of Table A1 show that the results in Table 2 are not driven by average health of adults at baseline. However, the corresponding results in Panel B of Table A1 imply that the results are driven by households with elderly in poor health at the baseline.

${ }^{16}$ We find the level of education is, in general, higher for men than for women; and this pattern is stronger for the elderly. 
age group, the program has a large, negative and statistically significant effect on hospitalization in the year before the survey: $22 \%$ for women aged 18-59 and $23 \%$ for men aged 18-59. For elderly men (aged 60 and higher), the program effect on hospitalization is almost 60\%, though surprisingly the effect on elderly women is almost non-existent.

\subsection{Are the Effects Driven by the Primary Caregivers?}

Recall that the primary caregivers (or titulars) accompany their children to the health centres. The titulars are directly exposed to the program by accompanying their children to the health centres, having direct interactions with health practitioners and attending sessions on health, nutrition, and hygiene. So it is worth examining whether the titulars are affected differently compared to the other similar aged women in the household. To examine this we restrict the sample to treatment households and estimate the following regression:

$$
H_{i t}=\alpha_{0}+\alpha_{1} \text { Titular }_{i}+\alpha_{2} \text { Year }_{t}+\alpha_{3}\left(\text { Titular }_{i} \times \text { Year }_{t}\right)+\mathbf{X}_{i}^{\prime} \gamma+\epsilon_{i t}
$$

Titular is a dummy variable that takes the value of 1 if the woman is the titular, 0 otherwise. Here $\alpha_{3}$ is interpreted as the change in health outcomes for titulars relative to the change in health outcomes for the non-titulars. By restricting the estimating sample to treatment municipalities we investigate whether titulars (who have direct interactions with the health practitioners and attend sessions on health, nutrition and hygiene) are affected differently compared to other similar aged women. Note that the sample for this regression is restricted to treatment households as by definition we cannot identify any titular in the control household. Consequently, the program effect, thus defined, is not the same program effect as described using equation (1). We call the program effect defined by equation (2) as the within household program effect.

The regression results are presented in Panel A of Table 6, which show that titulars are not benefiting any more compared to the non-titulars within the treatment households: the estimated coefficient $\alpha_{3}$ is never statistically significant. There is no evidence of this within household program effect. So, within the treatment households, the titulars did not gain more than the 
other women.

To further investigate whether the program effect is driven primarily by the titulars, we restrict the sample to women aged 18-59 and exclude the titulars. Then we re-estimate equation (1), where the program effect is given by $\beta_{3}$. In this regression, the non-titular women aged 18-59 in treatment households are compared to all women aged 18-59 in control households. If the program effect is driven by the titulars then excluding the titulars from the estimating sample will weaken the overall effects (presented in Tables 4 and 5). The corresponding regression results are presented in Panel B of Table 6. The estimated program effects continue to be statistically significant and qualitatively similar to those presented for women in Tables 4 and 5. The results therefore do not appear to be driven by isolated improvements in the health of the titulars; indeed, what they bring back to the household is crucial (potentially in the form of better information and in the creation of better household level public goods).

To summarize our results: in the short run, there is evidence of spillover effects within the household, occurring through a significantly reduced likelihood of illness in the 15 days prior to the date of the survey. In the medium run the spillover effects are manifested by a significant reduction in the likelihood of being hospitalized in the one year prior to the survey. The overall effects are driven by the improvements in the health of the elderly (both males and females). Additionally, the effects are not driven by improvements in the health of the titulars.

\subsection{Additional Robustness}

\subsubsection{Balanced Sample}

In Table A2 in the Supplementary Appendix, we present the results (corresponding to the regression specification given by equation (1)) but for the balanced sample, i.e., restricting the estimating sample to individuals who are observed in both rounds of the survey. These estimates are qualitatively similar to those presented in Table 2, though the short run effect on reported illness in the last 15 days is slightly weaker and not statistically significant. 


\subsubsection{Excluding Early Treatment Municipalities}

While the baseline survey was designed to obtain pre-program information about the households, for political reasons the program actually started in 26 of the 57 treatment municipalities prior to the baseline survey. Households in these early treatment municipalities were therefore already receiving the cash transfers by the time the baseline survey was conducted. We examined the robustness of our results by excluding the early treatment sample and restricting the sample to those households residing in the 31 treatment municipalities where the baseline survey was conducted prior to the program becoming operational. We find that the spillover effects are unchanged when we exclude the early treatment municipalities. The corresponding regression results are presented in columns 1 and 2 of Table A3 in the supplementary appendix.

\subsubsection{Excluding Converted Municipalities}

As a part of government policy the program was expanded in 2006. A second follow up survey was conducted in 2005-2006, and by the time it happened, the program had been extended to 13 of the control municipalities. So, in the second follow up, these 13 municipalities can be thought of as being treatment municipalities. We call these the converted municipalities. In the results that we presented, we included these converted municipalities as control municipalities - the argument being that the change happened not long before the second follow up survey. We examine the robustness of our results by excluding these converted municipalities from the estimation sample and find that excluding these converted municipalities does not affect our results. The results are presented in columns 3 and 4 of Table A3 in the supplementary appendix.

\subsubsection{Difference-in-Difference using Propensity Score Matching}

To analyze the extent of the potential bias introduced by the non-random implementation of the treatment at municipality level, we estimate the intention to treat (ITT) effect of the program using a difference-in-difference propensity score matching (DID-PSM). We follow the Rosenbaum 
and Rubin (1983) methodology by estimating the predicted probability of program participation for all households in our sample based on observable characteristics, this is the propensity score $p(x) .{ }^{17}$ This propensity score is then used to construct the distribution of $p(x)$ for households in treatment municipalities and the distribution of $p(x)$ for households in control municipalities, the intersection between the two distributions defines the common support. The set of households that are in the common support are similar and by comparing those in treatment and control we are able to estimate an unbiased program effect. Table A4 in the supplementary appendix presents the comparison of characteristics across the unmatched and matched samples. There are no statistically significant differences between treatment and control households in the matched sample. Table A5 presents the first stage results from the propensity score matching exercise. Note that almost all of the controls used to predict the propensity score are statistically significant. Comparing households in the common support leads to a reduction on the mean bias by 80 percent. ${ }^{18}$ We estimate the average indirect effect on adults health using a kernel non-parametric matching estimator, which matches each household in the treatment group to a weighted average of all households in the control group.

The estimated program effects show that overall, the effects (both on illness and hospitalization) are stronger in the medium run. As with the results presented in Section 4.2, these results indicate that the program effects are stronger for women in the short run and are stronger for men in the medium run. The corresponding results are presented in Table A6 in the supplementary appendix, for the sample of all adults and separately for males and females. ${ }^{19}$

\subsubsection{Effects on Mortality}

In Table A7 we present the short (at the first follow up) and medium run (at the second follow up) program effects on whether any adult member of the household died in the reference period

\footnotetext{
${ }^{17}$ The set of observable characteristics used to compute the propensity score are identical to the ones used by Attanasio et al. (2010).

${ }^{18}$ Matching households with the same $p(x)$ assumes that assignment to treatment or control is random for individuals with the same propensity score. However, this method relies on the assumption of no significant differences between treatment and control households in terms of the unobservable characteristics.

${ }^{19}$ We are unable to run the corresponding regressions by age because of sample issues.
} 
(columns 1 and 2) and the total number of deaths of adults in the household in the reference period (columns 3 and 4). The reference period for the baseline is the previous 12 months; that for the first follow up is the period between the baseline survey and the first follow up survey. The reference period for the second follow up is defined by the period between the first and the second follow up surveys (previous 3 years). ${ }^{20}$ While the program effect is always negative, it is statistically significant (and meaningful) only in columns 1 and 3: in the short run, the program leads to a decline in the likelihood of any adult household member dying and in the total number of adult deaths in the household.

\subsubsection{Placebo Regressions}

To ensure that the program effects that we find on adult health is not simply a spurious effect, we consider a set of placebo regressions where the dependent variable are unlikely to be affected by the program. We re-estimate the regression given by the specification in equation (1), but using know how to read, know how to write and level of education attained as the dependent variable. The estimation sample includes all adults aged 18 and higher. The corresponding regression results are presented in Table A8: Panel A for the short run effects and Panel B for the medium run effects. The program effect is never statistically significant suggesting that the results in Table 2 are not driven by spurious effects.

\subsubsection{Effects on Household Composition}

It is possible that the FA program could have potentially affected the household in other ways. For example, it could have affected migration into or out of the household. To examine this question, we present in Table A9, the short run and the long run program effects on household composition. As the results in Panel A column 1 show, in the short run, there is a reduction in the proportion of adults in the household. This, as the results in Panel A column 3 imply, is driven by a decrease in the proportion of adult females (aged 18-59) in the household. In the medium

\footnotetext{
${ }^{20}$ The specifications in columns 2 and 4 are, therefore, problematic in a difference-in-difference setting as they compare changes in different time periods.
} 
run, (Panel B), we find that there is a reduction in the proportion of elderly in the household. There is no evidence of others moving in to the household as a result of the program (see column $6)$ in either the short run or the long run.

\section{Mechanisms}

What drives the estimated indirect program effects or spillovers? Using a simple model of household utility maximization subject to health production within the household and household budget constraint, we can show that the total indirect program effects (or spillovers) on non-targeted beneficiaries is the sum of an income effect, a household public goods effect and a contagion effect. Details of the theoretical framework are presented in Section A1 in the Appendix. Consider a case where the production of health within the household depends on both privately and publicly provided health inputs. Assume that the two kinds of health inputs are perfect substitutes. By providing some of the necessary health inputs to the targeted members of the household for free, the program (or the publicly provided health input) would reduce expenditures on privately provided health inputs. This could make more household resources available to the non-targeted members to increase their consumption of the private health input. Recall that these non-targeted members are not eligible for the publicly provided input. This additional resource (or income) can also be used to purchase or produce more of the consumption good, which can provide an additional (income) effect on the health of the non-targeted individuals within the household. This is the income effect. Second, the FA program provides information on health, nutrition and hygienic practices in the household, thereby enhancing the basket of household public good. This is the public good effect. The third component of this indirect effect is the positive (biological) contagion effect, which is generated by the reduction of disease transmission within the household as a result of improved health of children. Both the public goods effect and the contagion effects have a multiplier effect for all household members since better use of information and better health of an individual would positively affect the health of other members, which in turn have a feedback effect on the health of the individual and so on. 
Note that typically such a reduced form framework, as we have in Section A1, can clearly predict an overall spillover effect of the program on the non-targeted individuals, but it does not permit a separate measurement of each component of the transmission mechanism. Since all the components are positive and mutually reinforcing, the total spillover effect is expected to be positive. Neither Chaudhuri (2009) nor Ver Ploeg (2009) are unable to identify the channels. ${ }^{21}$ We can, however, go one step further. While we cannot decompose the total effect in these three components, we can identify which of these effects play the strongest role.

First we use the educational component of the FA program to examine how important additional income was in its effect on the health of non-targeted adults in the household. If the improvement in the health of the adults in the household is due to the additional inflow of income, we should obtain a positive program effect even when there are no children aged $0-6$ in the household, but there are children aged 7-17 in the household and therefore the household is eligible for income transfer, conditional on the children attending school. Recall that eligible households satisfying the attendance requirement received a per-child monthly subsidy of 14,000 pesos (US \$6.15) and 28,000 pesos (US $\$ 12.30$ ) for each child attending primary and secondary school respectively.

We restrict the sample to households with no children aged 0-6, but with at least one child aged 7-17. In this sample, the only way in which exposure to the program can affect adult health is through the income effect. ${ }^{22}$ We estimate a specification where we include a set of interaction effects interacting Program with dummies for the number of children aged 7-17 in the household $I$ (\# Children aged $7-17=j)=1$ if the number of children aged $7-17=j$ and 0 otherwise. The

\footnotetext{
${ }^{21}$ Ver Ploeg (2009) writes that it is not possible to tell whether this is due to increased food benefits that are then shared with the non participating children in the family or whether the income offset by the WIC benefits is used to improve the diets of nonparticipating members with other foods (page 425).

${ }^{22}$ In all regressions we control for labor supply including the number of hours worked. This helps us to isolate the program income effect from any labor supply income effect. The IFS-Econometria-SEI (2006) program report shows an increase in the job market participation by adults but no program effect on the number of hours worked.
} 
estimating equation is given by:

$$
\begin{aligned}
H_{i c t} & =\beta_{0}+\beta_{1} \text { Treatment }_{c}+\beta_{2} \text { Year }_{t}+\beta_{3} \text { Program }_{c t} \\
& +\sum_{j=2}^{6} \xi_{j}\left(\text { Program }_{c t} \times I(\# \text { Children aged } 7-17=j)\right) \\
& +\mathbf{X}_{i c}^{\prime} \gamma+\varepsilon_{i c t}
\end{aligned}
$$

The variation in the number of children aged $7-17$ in the household allows us to identify the income effect arising from the FA program. This is because each extra child in this age range increases the amount transferred to the household. The estimated coefficient of the non-interacted term Program $\left(\beta_{3}\right)$ gives us the effect for households with one child aged $7-17$; and $\xi_{j}$ gives the additional effect of having $j$ children in the household, $j=2,3,4,5,6$ (and higher). We can then compute the total effect (through additional resources flowing into the household) of having $j>1$ children aged 7-17 as $\beta_{3}+\xi_{j}$. The $\mathrm{p}-$ values for the joint tests are presented in the bottom panel of Table 7 , with the top panel presenting the estimated coefficients $\left(\beta_{3}\right.$ and $\left.\beta_{3}+\xi_{j}\right)$. Neither in the short run, nor in the medium run is the joint test $\beta_{3}+\xi_{j}=0$ consistently rejected (indeed in only one of the 20 cases is the total effect statistically significant), indicating that additional income (through the FA program) does not have any effect on either of the two health measures that we consider. There is therefore no evidence of an income effect.

Now to understand the relative importance of the public goods effect and the contagion effect, we examine if including the health of children mediates the program effect. One could view this as a test of the contagion effect, which is generated by the reduction of disease transmission as a result of better average health of children (the direct beneficiaries of the program) within the household. If including the health of the children indeed mediates the program effect on the health of adults, we can argue that the effect is driven through the contagion effect.

We start by estimating a regression of the form:

$$
H_{i h c, t+1}-H_{i h c, t}=\zeta_{0}+\zeta_{1} \text { Treatment }_{c}+\mathbf{X}_{i h c}^{\prime}+\varepsilon_{i h c, t}
$$


The estimated coefficient of $\zeta_{1}$ gives us the program effect. The dependent variable in this regression is the change in the health of an adult $i$ in household $h$ in municipality $c$ across two rounds of the survey. The Treatment dummy equals 1 if the household resides in a treatment municipality. This specification has the advantage of being able to control for individual fixed effects (this is a difference estimator).

To evaluate whether improvements in the health of the children in the household improve adults' health, we consider the following regression:

$$
H_{i h c, t+1}-H_{i h c, t}=\nu_{0}+\nu_{1}\left(\mathrm{ChH}_{h c, t+1}-\mathrm{ChH}_{h c, t}\right)+\mathbf{X}_{i h c}^{\prime}+\varepsilon_{i h c, t}
$$

The dependent variable is defined as in equation (4); $\mathrm{ChH}_{h c, t+1}-\mathrm{ChH}_{h c, t}$ denotes the change in the average health of children in household $h$ in municipality $c$ across two rounds of the survey. Here $\nu_{1}$ captures the direct effect of changes in children's health on the health of adults in the same household.

To separately account for the direct program effect and the effect operating through the health of children in the household, we estimate the following regression:

$$
H_{i h c, t+1}-H_{i h c, t}=\pi_{0}+\pi_{1} \text { Treatment }_{c}+\pi_{2}\left(\mathrm{ChH}_{h c, t+1}-\mathrm{ChH}_{h c, t}\right)+\mathbf{X}_{i h c}^{\prime}+\varepsilon_{i h c, t}
$$

Equations (4) and (5) are restricted versions of equation (6): in equation (4) we turn off any effect operating through changes in child health, while in equation (5) we do not allow a program effect on the health of adults in the household. A comparison of the estimated coefficients $\zeta_{1}$ in equation (4) and $\pi_{1}$ in equation (6) gives us an indicator of how much including the change in children's health mediates the overall program effect on the health of (non-targeted) adults in the household. If the effect of the program is driven by improvements in children's health, then $\pi_{1}$ will be smaller than $\zeta_{1}$.

We use the change in the proportion of children in the household that are stunted as our measure of change in health of children in the household. ${ }^{23}$ The estimating sample is restricted to households

\footnotetext{
${ }^{23}$ Stunting (or more generally height-for-age z-score) reflects the cumulative effect of under-nutrition and infections
} 
with non-missing height of at least one child in both rounds considered.

The regression results are presented in Table 8. Before we proceed, note that the regression results in column 1 of Table 8 shows that both in the short run and in the medium run, there is an improvement in average child health within the household as a result of FA; this direct effect is more precise in the short run.

Columns 2 and 5 of Table 8 presents the results corresponding to equation (4): the program effect on the change in the likelihood of an adult reporting being ill in the 15 days prior to the survey and on the change in the likelihood of an adult reporting hospitalization in the year prior to the survey respectively. Panel A presents the results at the first follow-up (short run effects) and Panel B those at the second follow-up (medium run effects). These results are qualitatively consistent with those presented in Table 2, though the results in column 2 of Table 8 are slightly weaker and more imprecise than those in column 1 of Table 2. The results corresponding to the regression specification given by equation (5) are presented in columns 3 and 6 . Improvements in child health (in this case a reduction in stunting) is associated with an improvement in adult's health and this effect is statistically significant for hospitalization (column 6). In columns 4 and 7 we present the regression results corresponding to the regression specification given by equation (6). The effect of a reduction in the proportion of children in the household stunted on the change in proportion of adults reporting ill or change in the proportion of adults reporting hospitalization remains the same and there is only a small change in the program effect. In particular comparing columns 2 and 4 we see that the likelihood of reporting illness changes from -0.0248 to -0.0246 percentage points in the short run (Panel A) and from -0.0231 to -0.0233 percentage points in the medium run (Panel B). The likelihood of being hospitalized in the last year changes from -0.0108 to -0.0114 percentage points in the short run and from -0.0300 to -0.0304 percentage points in the medium run. This suggests that changes in the health of children in the household does not strongly mediate the spillover effect of the program. There is no evidence supporting the contagion effect.

since birth and therefore, it can be interpreted as an indicator of poor environmental conditions. We define a child to be stunted if his/her height-for-age z-score is less than -1 The height-for-age z-score is calculated using the WHO Child Growth standards (WHO, 2019). 
In conjunction with the results presented in Table 7 , the results presented in Table 8 suggest that the most important driver of the program effect on the health of adults in the household is the household public good effect.

\section{Conclusion}

Conditional Cash Transfer programs are regarded as policy makers' vehicle of choice to provide benefits to poor households that can potentially break the vicious inter-generational cycle of poverty. While the stated aims of most CCT programs is to improve the health and nutritional status and educational attainment of children in poor households, we argue that the total program effects go beyond the direct effects on the health of children. This is because such programs can affect the health of non-targeted members of the household. These are the within household indirect or spillover effects of the program.

Using data from the Familias en Acción program in Colombia, we show that there are indeed strong spillover effects within households. In the short run, the stronger effects are on self-reported illness. Non-targeted individuals (adults) in treatment households were significantly less likely to report being ill in the 15 days prior to the survey compared to adults in control households. The effects persist over a longer period of time and indeed over time they lead to better long term health and a reduction in the severity of illness, captured by lower rates of hospitalization. Additionally, we find that the effects are quite heterogeneous: stronger for women and the elderly in the short run but for men in the medium run. The most plausible mechanisms is a household level public good operating through changes in behavior and not a relaxation of the household budget constraint as a result of the cash transfer or a reduction in the contagion of sickness as a result of children's improved health.

All of this can have significant effects on the inter-generational poverty cycle. Healthier adults are more productive and this increase in productivity of adults is likely to positively affect the human capital of the next generation. None of this is captured by examining only the effects on the targeted group. From the policy point of view, simply looking at the direct effects can 
result in significant underestimation of the effect of such CCT programs. Proper cost-benefit analysis of such CCT programs needs to take into account the improved health of the non-targeted individuals. 


\section{References}

Angelucci, M. and G. De Giorgi (2009). Indirect effects of an aid program: How do cash transfers affect ineligibles' consumption? American Economic Review 99(1), 486 - 508.

Attanasio, O., E. Battistin, E. Fitzsimons, and M. Vera-Hernandez (2005). How effective are conditional cash transfers? evidence from colombia. Technical report, Institute of Fiscal Studies.

Attanasio, O., E. Fitzsimons, A. Gomez, M. I. Gutierrez, C. Meghir, and A. Mesnard (2010). Children's schooling and work in the presence of a conditional cash transfer program in rural colombia. Economic Development and Cultural Change 58(2), $181-210$.

Attanasio, O., E. Fitzsimons, and n. Gomez, A. (2005). The impact of a conditional education subsidy on school enrolment in colombia. Technical report, Institute of Fiscal Studies.

Attanasio, O., L. C. Gomez, A. Gomez Rojas, and M. Vera-Hernandez (2004). Child health in rural colombia: Determinants and policy interventions. Economics and Human Biology 2(3), 411 - 438.

Attanasio, O., L. C. Gomez, P. Heredia, and M. Vera-Hernandez (2005). The short-term impact of a conditional cash subsidy on child health and nutrition in colombia. Technical report, Institute of Fiscal Studies.

Attanasio, O. and A. Mesnard (2006). The impact of a conditional cash transfer programme on consumption in colombia. Fiscal Studies 27(4), 421-442.

Avitabile, C. (2011). Spillover effects in healthcare programs: Evidence on social norms and information sharing. CSEF Working Papers 271, Centre for Studies in Economics and Finance (CSEF), University of Naples, Italy.

Baez, J. E. and A. Camacho (2011). Assessing the long-term effects of conditional cash transfers on human capital: evidence from colombia. Technical report, World Bank.

Baird, S., C. McIntosh, and B. Özler (2011). Cash or condition? evidence from a cash transfer experiment. The Quarterly Journal of Economics 126(4), 1709-1753.

Bastagli, F., J. Hagen-Zanker, L. Harman, V. Barca, G. Sturge, and T. Schmidt (2016). Cash transfers: what does the evidence say? a rigorous review of programme impact and of the role of design and implementation features. Report, ODI.

Behrman, J. R. and A. B. Deolalikar (1988). Health and nutrition. In H. Chenery and T. Srinivasan (Eds.), Handbook of Development Economics, Volume 1 of Handbook of Development Economics, Chapter 14, pp. 631-711. Elsevier.

Behrman, J. R. and J. Hoddinott (2005). Programme evaluation with unobserved heterogeneity and selective implementation: The mexican progresa impact on child nutrition. Oxford Bulletin of Economics and Statistics 67(4), $547-569$.

Bobba, M. and J. Gignoux (2019). Neighborhood effects in integrated social policies. World Bank Economic Review Forthcoming.

Bobonis, G. J. and F. Finan (2009). Neighborhood peer effects in secondary school enrollment decisions. Review of Economics and Statistics $91(4), 695-716$.

Bustelo, M. (2012). Who else is Benefiting from Conditional Cash Transfer Programs? Indirect Effects on Siblings in Nicaragua. Ph. D. thesis, University of Illinois at Urbana-Champaign.

Chaudhuri, A. (2009). Spillover impacts of a reproductive health program on elderly women in rural bangladesh. Journal of Family and Economic Issues 30(2), 113 - 125.

Chioda, L., J. M. P. De Mello, and R. R. Soares (2016). Spillovers from conditional cash transfer programs: Bolsa familia and crime in urban brazil. Economics of Education Review 54, $306-320$. 
Crost, B., J. H. Felter, and P. B. Johnston (2016). Conditional cash transfers, civil conflict and insurgent influence: Experimental evidence from the philippines. Journal of Development Economics 118, 171 - 182.

DFID (2011). Cash transfers evidence paper. Technical report, DFID Evidence Paper Policy Division. London, UK.

Economist, T. (2010). Give the poor money.

Fiszbein, A. and N. R. Schady (2009). Conditional cash transfers: reducing present and future poverty. The World Bank.

Fitzgerald, J., P. Gottschalk, and R. Moffitt (1998). An analysis of sample attrition in panel data: The michigan panel study of income dynamics. Journal of Human Resources 33(2), $251-299$.

Fitzsimons, E. and A. Mesnard (2008). Are boys and girls affected differently when the household head leaves for good? evidence from school and work choices in colombia. Technical report, CEPR Discussion Paper DP7040.

Gertler, P. (2004). Do conditional cash transfers improve child health? evidence from progresa's control randomized experiment. American Economic Review, Papers and Proceedings 94(2), 336 - 341.

Gertler, P. and S. Boyce (2001). An experiment in incentive-based welfare:the impact of progesa on health in mexico. Technical report, University of California, Berkeley.

IFS (2004). Baseline report on the evaluation of familias en accion. Technical report, Institute of Fiscal Studies.

IFS-Econometria-SEI (2006). Evaluación de impacto del programa familias en acción: Informe final - diciembre de 2006 (impact evaluation of the familias en accion program: Final report - december 2006. Technical report, IFS-Econometria-SEI.

Kazianga, H., D. de Walque, and H. Alderman (2013). School feeding programs, intrahousehold allocation and the nutrition of siblings: Evidence from a randomized trial in rural burkina faso. Journal of Development Economics http://dx.doi.org/10.1016/j.jdeveco.2013.08.00\%.

Lagarde, M., A. Haynes, and N. Palmer (2007). Conditional cash transfers for improving uptake of health interventions in low- and middle-income countries. Journal of American Medical Association 298(16), 1900-1910.

Lalive, R. and M. A. Cattaneo (2009). Social interactions and schooling decisions. Review of Economics and Statistics $91(3), 457-477$.

Maluccio, J. and R. Flores (2005). Impact evaluation of a conditional cash transfer program: The nicaraguan red de proteccion social. Technical report, IFPRI, Research Report 141, Washington D.C.

Rosenbaum, P. and D. Rubin (1983). The central role of the propensity score in observational studies for causal effects. Biometrika 70, $41-55$.

Velez, C. E., E. Castano, and R. Deutsch (1998). An economic interpretation of colombia's sisben: a composite welfare index derived from the optimal scaling algorithm. Technical report, Inter American Development Bank.

Ver Ploeg, M. (2009). Do benefits of u.s. food assistance programs for children spillover to older children in the same household? Journal of Family and Economic Issues 30, 412 - 427.

WHO (2019). Nutrition landscape information system (nlis) country profile indicators: interpretation guide. Guide, World Health Organization. 


\section{Table 1: Baseline Descriptive Statistics}

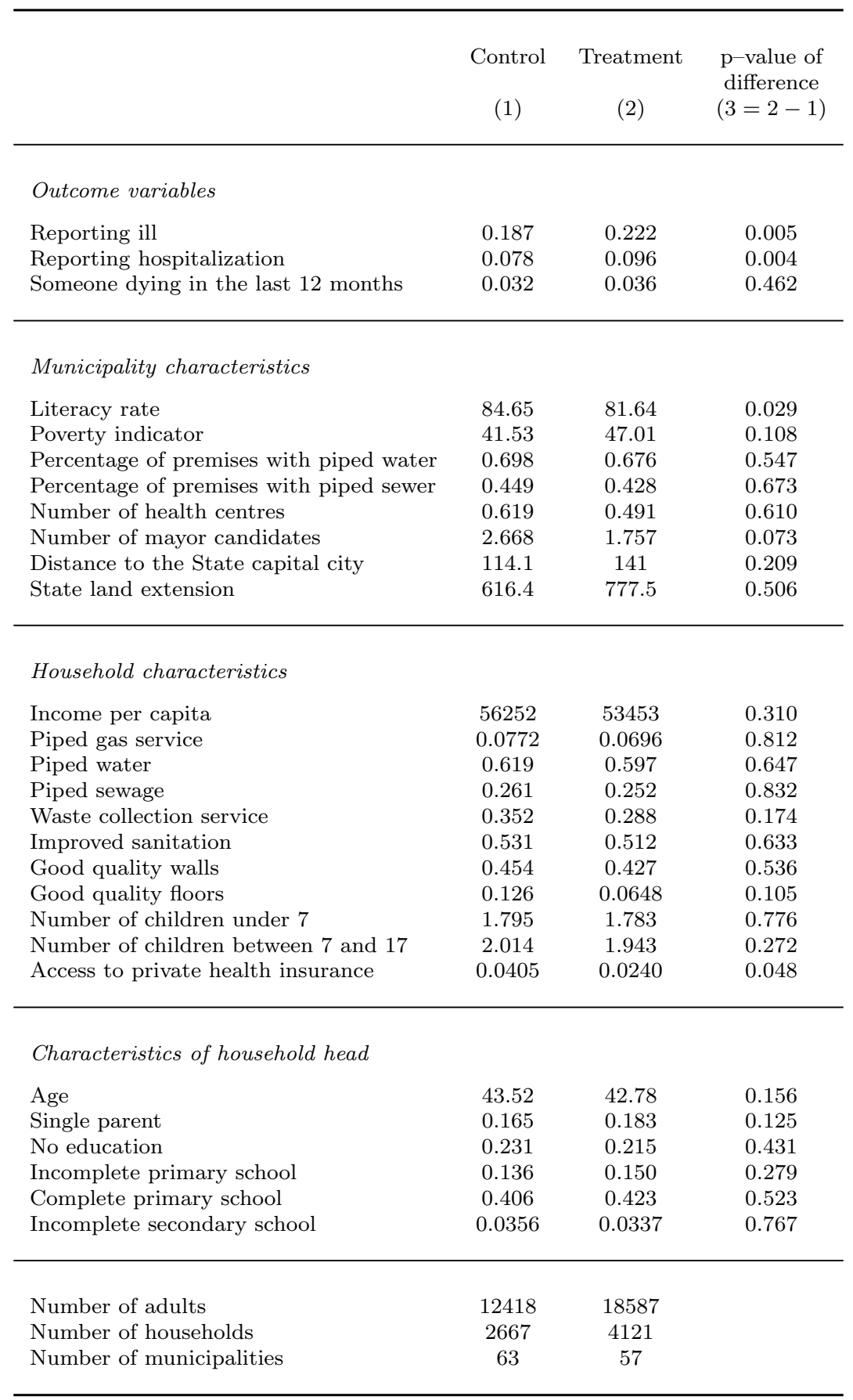

Notes: Descriptive statistics on the 6788 households who were surveyed both in the baseline and the first follow-up. Standard errors of differences (not presented but available on request) are clustered at the municipality level. 
Table 2: Program Effects, All Adults Ages 18 and Older

\begin{tabular}{lcc}
\hline & $\begin{array}{c}\text { Reporting ill } \\
(1)\end{array}$ & $\begin{array}{c}\text { Reporting hospitalization } \\
(2)\end{array}$ \\
\hline & & \\
Panel A: First follow up & & \\
Program & $-0.0282^{*}$ & -0.0079 \\
& $(0.0146)$ & $(0.0070)$ \\
Mean control at baseline & 0.187 & 0.0779 \\
\% effect & -15.08 & -10.14 \\
Sample size & 31,005 & 31,005 \\
\hline & & \\
Panel B: Second follow up & & $-0.0194^{* * *}$ \\
Program & -0.0209 & $(0.0069)$ \\
& $(0.0184)$ & 0.0779 \\
Mean control at baseline & 0.187 & -24.90 \\
\% effect & -11.18 & 26,875 \\
Sample size & 26,874 & \\
\hline
\end{tabular}

Notes: Dependent variable in column 1 is whether the individual reported being ill during the 15 days prior to the survey. Dependent variable in column 2 is whether the individual was hospitalized in the one year prior to the survey. Marginal effects from Probit regressions presented. Regressions control for Treatment Tr $_{c}$ and Year T $_{t}$ and a set of individual, household and municipality characteristics. Significance: ${ }^{* * *}: 1 \% *^{* *}: 5 \%{ }^{*}: 10 \%$. Standard errors clustered by municipality. 
Table 3: Program Effects, by Age

\begin{tabular}{lcccc}
\hline & \multicolumn{3}{c}{ Reporting ill } & Reporting hospitalization \\
\cline { 2 - 5 } & $\begin{array}{c}18-59 \\
(1)\end{array}$ & $\begin{array}{c}60 \text { and higher } \\
(2)\end{array}$ & $\begin{array}{c}18-59 \\
(3)\end{array}$ & $\begin{array}{c}60 \text { and higher } \\
(4)\end{array}$ \\
& & & & \\
& & & & \\
Panel A: First follow up & & & & \\
Program & -0.0234 & $-0.0864^{* *}$ & -0.0087 & 0.0086 \\
& $(0.0145)$ & $(0.0415)$ & $(0.0071)$ & $(0.0259)$ \\
Mean control at baseline & 0.175 & 0.353 & 0.0751 & 0.115 \\
\% effect & -13.37 & -24.48 & -11.58 & 7.48 \\
Sample size & 28,604 & 2,401 & 28,604 & 2,401 \\
\hline & & & & \\
Panel B: Second follow up & & & & \\
Program & -0.0194 & -0.0437 & $-0.0165^{* *}$ & $-0.0479^{*}$ \\
& $(0.0178)$ & $(0.0436)$ & $(0.0071)$ & $(0.0248)$ \\
Mean control at baseline & 0.175 & 0.353 & 0.0751 & 0.115 \\
\% effect & -11.09 & -12.38 & -21.97 & -41.65 \\
Sample size & 24,883 & 1,991 & 24,883 & 1,992 \\
\hline & & & & \\
\hline
\end{tabular}

Notes: Dependent variable in columns $1-2$ is whether the individual reported being ill during the 15 days prior to the survey. Dependent variable in columns $3-4$ is whether the individual was hospitalized in the one year prior to the survey. Marginal effects from Probit regressions presented. Regressions control for Treatment $_{c}$ and Year Y $_{t}$ and a set of individual, household and municipality characteristics. Significance: ${ }^{* * *}: 1 \% ;^{* *}: 5 \% ;^{*}: 10 \%$. Standard errors clustered by municipality. 
Table 4: Gender and Age Specific Program Effects on Reporting Being Ill in the 15 Days Prior to the Follow-Up Survey

\begin{tabular}{lcccccc}
\hline & \multicolumn{3}{c}{ Female } & \multicolumn{3}{c}{ Male } \\
& All & $18-59$ & 60 or higher & All & $18-59$ & 60 or higher \\
& $(1)$ & $(2)$ & $(3)$ & $(4)$ & $(5)$ & \\
& & & & & & \\
& & & & & & \\
Panel A: First follow up & & & & & \\
Program & $-0.0296^{*}$ & -0.0259 & -0.0849 & -0.0272 & -0.0210 & $-0.0915^{*}$ \\
& $(0.0166)$ & $(0.0165)$ & $(0.0579)$ & $(0.0169)$ & $(0.0173)$ & $(0.0506)$ \\
Mean control at baseline & 0.201 & 0.191 & 0.375 & 0.173 & 0.158 & 0.337 \\
\% effect & -14.73 & -13.56 & -22.64 & -15.72 & -13.29 & -27.15 \\
Sample size & 15,883 & 14,862 & 1,021 & 15,122 & 13,742 & 1,380 \\
\hline & & & & & & \\
Panel B: Second follow up & & & & & & \\
Program & -0.0079 & -0.0094 & 0.0332 & $-0.0343^{*}$ & -0.0300 & $-0.0976^{* *}$ \\
& $(0.0218)$ & $(0.0206)$ & $(0.0778)$ & $(0.0185)$ & $(0.0185)$ & $(0.0442)$ \\
Mean control at baseline & 0.201 & 0.191 & 0.375 & 0.173 & 0.158 & 0.337 \\
\% effect & -3.93 & -4.92 & 8.85 & -19.83 & -18.99 & -28.96 \\
Sample size & 13,993 & 13,140 & 853 & 12,881 & 11,743 & 1,138 \\
\hline
\end{tabular}

Notes: Dependent variable is whether the individual reported being ill during the 15 days prior to the survey. Marginal effects from Probit regressions presented. Regressions control for Treatment $_{c}$ and Year $_{t}$ and a set of individual, household and municipality characteristics. Significance: ${ }^{* * *}$ : $1 \% ;^{* *}: 5 \% ;^{*}: 10 \%$. Standard errors clustered by municipality. 


\section{Table 5: Gender and Age Specific Program Effects on Reporting Being}

Hospitalized in the Year Prior to the Survey

\begin{tabular}{|c|c|c|c|c|c|c|}
\hline & \multicolumn{3}{|c|}{ Female } & \multicolumn{3}{|c|}{ Male } \\
\hline & $\begin{array}{l}\text { All } \\
(1)\end{array}$ & $\begin{array}{c}18-59 \\
(2)\end{array}$ & $\begin{array}{c}60 \text { or higher } \\
(3)\end{array}$ & $\begin{array}{l}\text { All } \\
(4)\end{array}$ & $\begin{array}{c}18-59 \\
(5)\end{array}$ & $\begin{array}{c}60 \text { or higher } \\
(6)\end{array}$ \\
\hline \multicolumn{7}{|l|}{ Panel A: First follow up } \\
\hline Program & $\begin{array}{c}-0.0164^{*} \\
(0.0099)\end{array}$ & $\begin{array}{l}-0.0153 \\
(0.0102)\end{array}$ & $\begin{array}{l}-0.0228 \\
(0.0382)\end{array}$ & $\begin{array}{l}-0.0013 \\
(0.0073)\end{array}$ & $\begin{array}{l}-0.0040 \\
(0.0069)\end{array}$ & $\begin{array}{c}0.0290 \\
(0.0325)\end{array}$ \\
\hline $\begin{array}{l}\text { Mean control at baseline } \\
\% \text { effect }\end{array}$ & $\begin{array}{l}0.0896 \\
-18.30\end{array}$ & $\begin{array}{l}0.0884 \\
-17.31\end{array}$ & $\begin{array}{c}0.108 \\
-21.11\end{array}$ & $\begin{array}{l}0.0659 \\
-1.97\end{array}$ & $\begin{array}{l}0.0611 \\
-6.55\end{array}$ & $\begin{array}{l}0.119 \\
24.37\end{array}$ \\
\hline Sample size & 15,883 & 14,862 & 1,021 & 15,122 & 13,742 & 1,380 \\
\hline \multicolumn{7}{|l|}{ Panel B: Second follow up } \\
\hline Program & $\begin{array}{c}-0.0190^{* *} \\
(0.0092)\end{array}$ & $\begin{array}{c}-0.0198^{* *} \\
(0.0096)\end{array}$ & $\begin{array}{l}-0.0026 \\
(0.0414)\end{array}$ & $\begin{array}{l}-0.0203^{* * *} \\
(0.0079)\end{array}$ & $\begin{array}{l}-0.0143^{*} \\
(0.0078)\end{array}$ & $\begin{array}{c}-0.0703^{* *} \\
(0.0279)\end{array}$ \\
\hline $\begin{array}{l}\text { Mean control at baseline } \\
\% \text { Effect }\end{array}$ & $\begin{array}{l}0.0896 \\
-21.21\end{array}$ & $\begin{array}{l}0.0884 \\
-22.40\end{array}$ & $\begin{array}{l}0.108 \\
-2.41\end{array}$ & $\begin{array}{l}0.0659 \\
-30.84\end{array}$ & $\begin{array}{l}0.0611 \\
-23.40\end{array}$ & $\begin{array}{c}0.119 \\
-59.08\end{array}$ \\
\hline Sample size & 13,994 & 13,140 & 854 & 12,881 & 11,743 & 1,138 \\
\hline
\end{tabular}

Notes: Dependent variable is whether the individual was hospitalized in the one year prior to the survey. Marginal effects from Probit regressions presented. Regressions control for Treatment and $_{c}$ Yar $_{t}$ and a set of individual, household and municipality characteristics. Significance: ${ }^{* * *}: 1 \%$; $^{* *}: 5 \%^{*}: 10 \%$. Standard errors clustered by municipality. 
Table 6: Direct and Indirect Program Effects on Women Ages 18-59

\begin{tabular}{|c|c|c|c|c|}
\hline & \multicolumn{2}{|c|}{ First follow up } & \multicolumn{2}{|c|}{ Second follow up } \\
\hline & $\begin{array}{l}\text { Reporting ill } \\
(1)\end{array}$ & $\begin{array}{c}\text { Reporting hospitalization } \\
(2)\end{array}$ & $\begin{array}{c}\text { Reporting ill } \\
(3)\end{array}$ & $\begin{array}{c}\text { Reporting hospitalization } \\
(4)\end{array}$ \\
\hline \multicolumn{5}{|c|}{ Panel A: Titulars and non-titulars in treatment households } \\
\hline Within household program & $\begin{array}{c}0.0114 \\
(0.0159)\end{array}$ & $\begin{array}{c}0.0001 \\
(0.0132)\end{array}$ & $\begin{array}{c}0.0018 \\
(0.0211)\end{array}$ & $\begin{array}{c}0.0169 \\
(0.0149)\end{array}$ \\
\hline $\begin{array}{l}\text { Mean control at baseline (Non-titular) } \\
\% \text { effect }\end{array}$ & $\begin{array}{l}0.24 \\
4.75\end{array}$ & $\begin{array}{l}0.11 \\
0.09\end{array}$ & $\begin{array}{l}0.24 \\
0.75\end{array}$ & $\begin{array}{c}0.11 \\
15.36\end{array}$ \\
\hline Sample size & 8,993 & 8,993 & 8,004 & 8,004 \\
\hline \multicolumn{5}{|c|}{ Panel B: Non-titulars in treatment and all women in control households } \\
\hline Program & $\begin{array}{c}-0.0389^{* *} \\
(0.0177)\end{array}$ & $\begin{array}{l}-0.0142 \\
(0.0115)\end{array}$ & $\begin{array}{l}-0.0156 \\
(0.0248)\end{array}$ & $\begin{array}{c}-0.0222^{*} \\
(0.0118)\end{array}$ \\
\hline $\begin{array}{l}\text { Mean control at baseline } \\
\% \text { effect }\end{array}$ & $\begin{array}{c}0.20 \\
-19.45\end{array}$ & $\begin{array}{c}0.09 \\
-15.78\end{array}$ & $\begin{array}{c}0.20 \\
-7.80\end{array}$ & $\begin{array}{c}0.09 \\
-24.67\end{array}$ \\
\hline Sample size & 9,146 & 9,146 & 7,970 & 7,970 \\
\hline
\end{tabular}

Notes

Significance: ${ }^{* * *}: 1 \%{ }^{* *}: 5 \% ;^{*}: 10 \%$. Standard errors clustered by municipality. Regressions control for a set of individual, household and municipality characteristics. Regressions in Panel A also control for Titular $i$ and Yeart. Regressions in Panel B also control for Treatment $_{c}$ and Year $_{t}$. Titulars are defined as those who were identified as the child's main caregiver at the baseline. 
Table 7: Is the Improvement in Health the Result of an Income Effect?

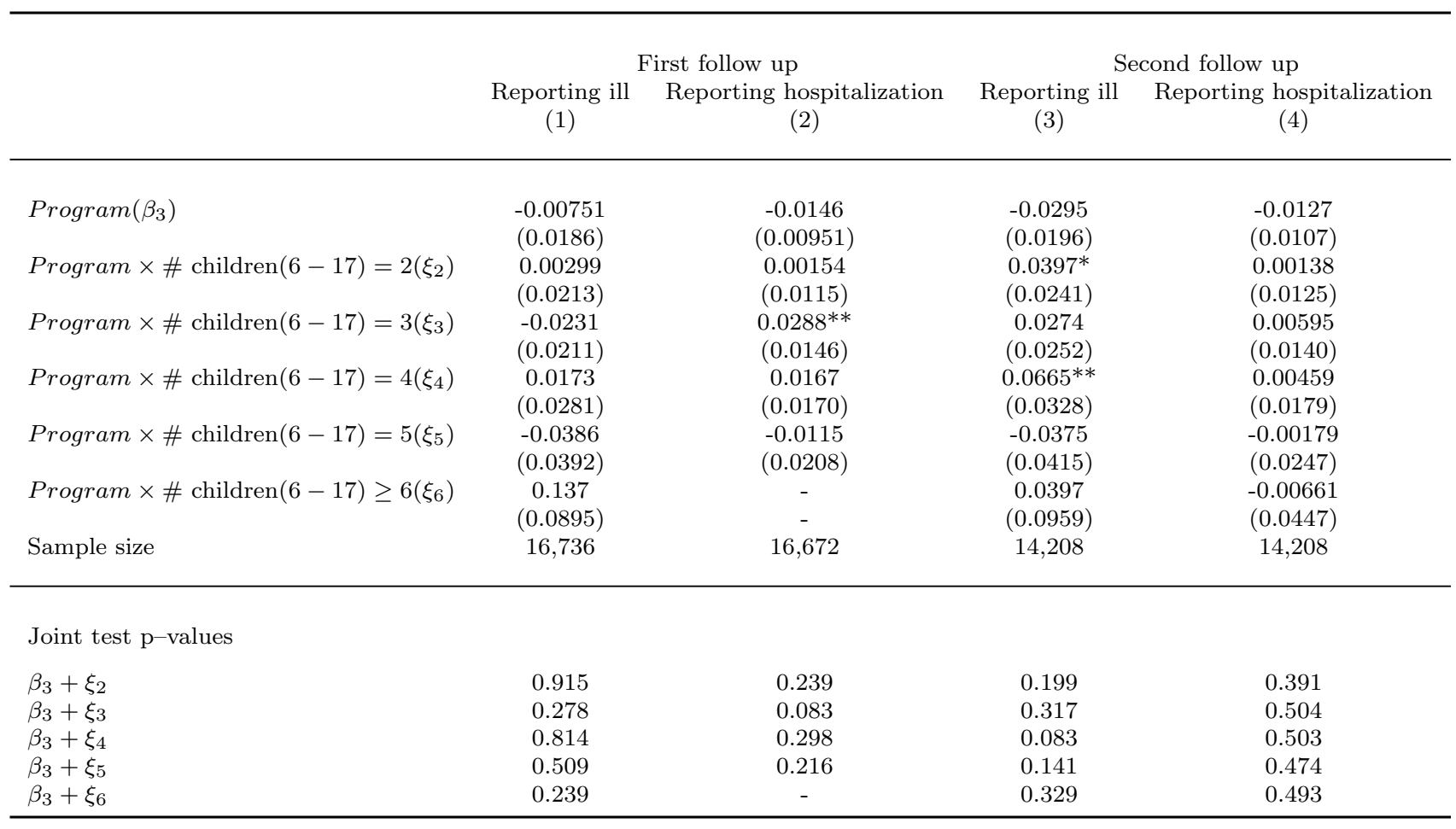

Notes: Significance: ${ }^{* * *}: 1 \% ;^{* *}: 5 \% ;^{*}: 10 \%$. Standard errors clustered by municipality. Regressions control for a set of individual, household and municipality characteristics. Sample restricted to households with no children ages $0-6$. 
Table 8: Does a Change in Child Health Mediate the Direct Program Effect?

\begin{tabular}{|c|c|c|c|c|c|c|c|}
\hline & \multirow{3}{*}{$\begin{array}{c}\text { Direct effect } \\
\text { Change in } \\
\text { proportion stunted } \\
\text { (1) }\end{array}$} & \multicolumn{6}{|c|}{ Spillover effect } \\
\hline & & \multicolumn{3}{|c|}{$\begin{array}{l}\text { Change in } \\
\text { reporting ill }\end{array}$} & \multicolumn{3}{|c|}{$\begin{array}{l}\text { Change in } \\
\text { reporting hospitalization }\end{array}$} \\
\hline & & $(2)$ & $(3)$ & $(4)$ & $(5)$ & $(6)$ & $(7)$ \\
\hline \multicolumn{8}{|l|}{ Panel A: First follow up } \\
\hline Program & $\begin{array}{l}-0.0169^{*} \\
(0.0102)\end{array}$ & $\begin{array}{l}-0.0248 \\
(0.0157)\end{array}$ & & $\begin{array}{l}-0.0246 \\
(0.0157)\end{array}$ & $\begin{array}{l}-0.0108 \\
(0.0079)\end{array}$ & & $\begin{array}{l}-0.0114 \\
(0.0079)\end{array}$ \\
\hline Change in proportion stunted & & & $\begin{array}{c}0.0120 \\
(0.0179)\end{array}$ & $\begin{array}{c}0.0111 \\
(0.0178)\end{array}$ & & $\begin{array}{c}-0.0316^{* * *} \\
(0.0101)\end{array}$ & $\begin{array}{c}-0.0320^{* * * *} \\
(0.0101)\end{array}$ \\
\hline Constant & $\begin{array}{c}0.0032 \\
(0.1392)\end{array}$ & $\begin{array}{c}0.2100 \\
(0.1448)\end{array}$ & $\begin{array}{c}0.1714 \\
(0.1421)\end{array}$ & $\begin{array}{c}0.2100 \\
(0.1448)\end{array}$ & $\begin{array}{c}0.0254 \\
(0.0981)\end{array}$ & $\begin{array}{c}0.0077 \\
(0.1052)\end{array}$ & $\begin{array}{c}0.0255 \\
(0.0973)\end{array}$ \\
\hline Sample size & 10,621 & 10,621 & 10,621 & 10,621 & 10,621 & 10,621 & 10,621 \\
\hline \multicolumn{8}{|l|}{ Panel B: Second follow up } \\
\hline Program & $\begin{array}{l}-0.0173 \\
(0.0129)\end{array}$ & $\begin{array}{l}-0.0231 \\
(0.0168)\end{array}$ & & $\begin{array}{l}-0.0233 \\
(0.0168)\end{array}$ & $\begin{array}{c}-0.0300^{* * *} \\
(0.0080)\end{array}$ & & $\begin{array}{c}-0.0304^{* * *} \\
(0.0080)\end{array}$ \\
\hline Change in proportion stunted & & & $\begin{array}{l}-0.0124 \\
(0.0182)\end{array}$ & $\begin{array}{l}-0.0131 \\
(0.0181)\end{array}$ & & $\begin{array}{c}-0.0204^{*} \\
(0.0113)\end{array}$ & $\begin{array}{l}-0.0212^{*} \\
(0.0113)\end{array}$ \\
\hline Constant & $\begin{array}{c}0.0218 \\
(0.1239)\end{array}$ & $\begin{array}{c}0.1801 \\
(0.1819)\end{array}$ & $\begin{array}{c}0.1433 \\
(0.1880)\end{array}$ & $\begin{array}{c}0.1804 \\
(0.1818)\end{array}$ & $\begin{array}{c}0.0254 \\
(0.0899)\end{array}$ & $\begin{array}{l}-0.0226 \\
(0.0962)\end{array}$ & $\begin{array}{c}0.0259 \\
(0.0899)\end{array}$ \\
\hline Sample size & 8,338 & 8,338 & 8,338 & 8,338 & 8,339 & 8,339 & 8,339 \\
\hline
\end{tabular}

Notes: Significance: ${ }^{* * *}: 1 \%$ ** $^{*} 5 \% ;^{*}: 10 \%$. Standard errors clustered by municipality. Regressions control for a set of individual, household and municipality characteristics. In column 1 , the dependent variable is the change in the proportion of children within the household that are stunted, where a child is defined as stunted if height-for-age z-score is $<-1$. In columns $2-4$, the dependent variable is the change in individual $i$ residing in household $h$ reporting being ill in the 15 days prior to the survey. In columns $5-7$, the dependent variable is the change in individual $i$ residing in household $h$ reporting being hospitalized in the year prior to the survey. 


\section{Appendix}

\section{A1 Theoretical Framework}

To explain the mechanisms by which a spillover effect might result, we use a stylistic unitary household model (see Behrman and Deolalikar, 1988, Chaudhuri, 2009). Consider a household with $n$ members. The utility function that defines the preferences of the household is well behaved and can be written as:

$$
U_{j}=U_{j}\left(H_{i j}, X_{i j}, Z_{i j}\right)
$$

where $U_{j}$ is the utility of the $j^{t h}$ household, $H_{i j}$ represents the vector of the health of individuals $i=1,2, \ldots, n$ in household $j$ and $Z_{i j}$ represents the vector of health inputs and $X_{i j}$ represents the vector of all other consumption goods of household members. Utility maximization is subject to the household budget constraint and the health production functions of all the individuals in the household.

The health production function of the household members can be written as:

$$
H_{i j}=H\left(X_{i j}, Z_{i j}, W_{j}(F), H_{-i j} ; \mu\right)
$$

Health production within the household depends on the use of health inputs $\left(Z_{i j}\right)$, consumption of all other goods $\left(X_{i j}\right)$, household public good $\left(W_{j}\right)$, health of all other members in the household excluding oneself $\left(H_{-i j}\right)$ and all the observed and unobserved endowments of the household $(\mu)$. We subdivide the household into two groups: the targeted or $T$ members (for example children aged $0-6$ who are the direct beneficiaries of the program) and the other or $O$ members of the household who are not the targeted beneficiaries. Also $H_{-i j}=\left\{H_{1 j}, \ldots, H_{i-1 j}, H_{i+1 j}, \ldots, H_{n j}\right\}$ and $H_{i j} \in\left[H_{i j}^{T}, H_{i j}^{O}\right]$. Health inputs $\left(Z_{i j}\right)$ depends on health inputs provided by the FA program $\left(z^{F A}\right)$ and private health inputs $\left(z^{P}\right)$, so that we can write

$$
Z_{i j}=Z\left(z_{j}^{F A}(F), z_{i j}^{P}\right)
$$


Since $z^{F A}$ is only available to targeted individuals residing in the treatment municipalities, it is a function of the health program $(F)$. Note that the health and nutrition component of the FA program involves a lump sum payment to the household, irrespective of the number of targeted individuals. Hence $z_{j}^{F A}(F)$ is defined at the household level. Likewise household public good $(W)$ is also a function of $F$, generated when the program is present in the household. Define $F=1$ when the program is available (for households with targeted individuals in the treatment municipalities) and $F=0$ if otherwise. Then $z_{j}^{F A}(F)=0$ if $F=0$ and $z_{j}^{F A}(F)>0$ if $F=1$. Likewise $W_{j}(F)=0$ if $F=0$ and $W_{j}(F)>0$ if $F=1$.

The household budget constraint when $Y$ is the pooled household income, $p_{z^{P}}$ and $p_{x}$ are prices of the private health inputs and consumption goods respectively can be written as:

$$
\sum_{i} p_{x} X_{i j}+\sum_{i} p_{z^{P}} z_{i j}^{P}=Y+z_{j}^{F A}(F)
$$

Maximizing utility (given by equation (A1)) subject to the production constraints (given by equations (A2) and (A3)) and the budget constraint (given by equation (A4)), the reduced form demand functions for health inputs, consumption and outcome variables can be written as:

$$
\left\{H_{i j}^{T}, H_{i j}^{O}, Z_{i j}, W_{j}, X_{i j}\right\}=f\left(p_{x}, p_{z^{P}}, Y_{j} ; F, \mu_{j}\right)
$$

Program intervention (through $F$ ) that changes any of the right-hand side variables will change the allocation of resources and outcomes within the households to conform to the optimizing allocation. The impact of the program on the targeted and non-targeted population can therefore 
be written as:

$$
\begin{aligned}
\frac{\partial H_{i j}^{T}}{\partial F}= & \underbrace{\left(\frac{\partial H^{T}}{\partial X_{i j}}\right)\left(\frac{\partial X_{i j}}{\partial F}\right)+\left(\frac{\partial H^{T}}{\partial z_{i j}^{P}}\right)\left(\frac{\partial z_{i j}^{P}}{\partial F}\right)}_{\text {Income effect }}+\underbrace{\left(\frac{\partial H^{T}}{\partial W_{j}}\right)\left(\frac{\partial W_{j}}{\partial F}\right)}_{\text {Household public good effect }} \\
& +\underbrace{\left(\frac{\partial H^{T}}{\partial H_{-i j}}\right)\left(\frac{\partial H_{-i j}}{\partial F}\right)}_{\text {Contagion effect }}+\underbrace{\left(\frac{\partial H^{T}}{\partial z_{j}^{F A}}\right)\left(\frac{\partial z_{j}^{F}}{\partial F}\right)}_{\text {Direct effect }} \\
\frac{\partial H_{i j}^{O}}{\partial F}= & \underbrace{\left(\frac{\partial H^{O}}{\partial X_{i j}}\right)\left(\frac{\partial X_{i j}}{\partial F}\right)+\left(\frac{\partial H^{O}}{\partial z_{i j}^{P}}\right)\left(\frac{\partial z_{i j}^{P}}{\partial F}\right)}_{\text {Income effect }}+\underbrace{\left(\frac{\partial H^{O}}{\partial W_{j}}\right)\left(\frac{\partial W_{j}}{\partial F}\right)}_{\text {Household public good effect }} \\
& +\underbrace{\left(\frac{\partial H^{O}}{\partial H_{-i j}}\right)\left(\frac{\partial H_{-i j}}{\partial F}\right)}_{\text {Contagion effect }}
\end{aligned}
$$

The focus of this paper is on spillovers, and therefore we are interested in the effects captured through equation (A7). The first two terms $\left[\left(\frac{\partial H^{O}}{\partial X_{i j}}\right)\left(\frac{\partial X_{i j}}{\partial F}\right)+\left(\frac{\partial H^{O}}{\partial z_{i j}^{P}}\right)\left(\frac{\partial z_{i j}^{P}}{\partial F}\right)\right]$ denote the income effect, the third term $\left[\left(\frac{\partial H^{O}}{\partial W_{j}}\right)\left(\frac{\partial W_{j}}{\partial F}\right)\right]$ denotes the household public good effect and the last term $\left[\left(\frac{\partial H^{O}}{\partial H_{-i j}}\right)\left(\frac{\partial H_{-i j}}{\partial F}\right)\right]$ denotes the contagion effect. Note that the total effect on the targeted individuals (equation (A6)) has an additional term which is the direct effect of the program on those targeted (given specifically by the program requirement - regular attendance and check-ups in the health clinics). 


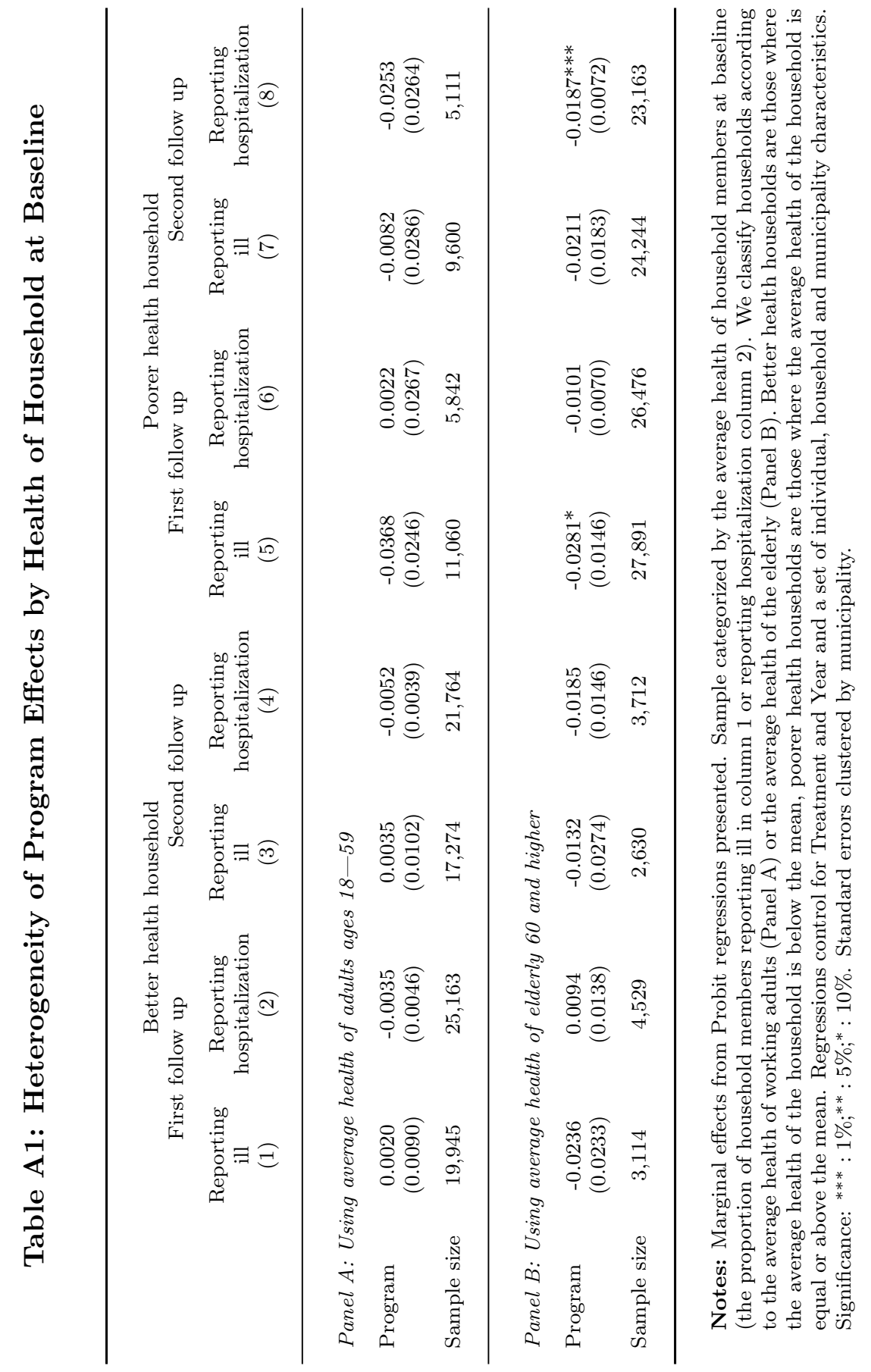


Table A2: Program Effects for All Adults ages 18 and higher in the Balanced Sample

\begin{tabular}{|c|c|c|c|c|}
\hline & \multicolumn{2}{|c|}{ First follow up } & \multicolumn{2}{|c|}{ Second follow up } \\
\hline & $\begin{array}{l}\text { Reporting ill } \\
(1)\end{array}$ & $\begin{array}{c}\text { Reporting hospitalization } \\
(2)\end{array}$ & $\begin{array}{l}\text { Reporting ill } \\
(3)\end{array}$ & $\begin{array}{c}\text { Reporting hospitalization } \\
(4)\end{array}$ \\
\hline Program & $\begin{array}{l}-0.0232 \\
(0.0146)\end{array}$ & $\begin{array}{l}-0.0074 \\
(0.0069)\end{array}$ & $\begin{array}{l}-0.0178 \\
(0.0189)\end{array}$ & $\begin{array}{l}-0.0185^{* * *} \\
(0.0069)\end{array}$ \\
\hline Sample size & 28,018 & 28,018 & 23,656 & 23,658 \\
\hline
\end{tabular}

Notes: Dependent variable in columns 1 and 3 is: whether the individual reported being ill during the 15 days prior to the survey. Dependent variable in columns 2 and 4 is whether the individual was hospitalized in the one year prior to the survey. Marginal effects from Probit regressions presented. Regressions control for Treatment Tr $_{c}$ and Year $_{t}$ and a set of individual, household and municipality characteristics. Sample restricted to individuals who are in observed in both rounds of the survey. Significance: ${ }^{* *}: 1 \% ;^{* *}: 5 \% ;^{*}: 10 \%$. Standard errors clustered by municipality. 


\section{Table A3: Program Effect when Excluding Early Treatment and Converted Municipalities}

\begin{tabular}{|c|c|c|c|c|}
\hline & \multirow{2}{*}{\multicolumn{2}{|c|}{$\begin{array}{c}\text { Excluding early treatment municipalities } \\
\text { First follow up }\end{array}$}} & \multicolumn{2}{|c|}{ Excluding converted municipalities } \\
\hline & & & & cond follow up \\
\hline & $\begin{array}{c}\text { Reporting ill } \\
(1)\end{array}$ & $\begin{array}{c}\text { Reporting hospitalization } \\
(2)\end{array}$ & $\begin{array}{c}\text { Reporting ill } \\
(3)\end{array}$ & $\begin{array}{c}\text { Reporting hospitalization } \\
(4)\end{array}$ \\
\hline Program & $\begin{array}{l}-0.0305^{*} \\
(0.0161)\end{array}$ & $\begin{array}{l}-0.0127 \\
(0.0098)\end{array}$ & $\begin{array}{l}-0.0224 \\
(0.0178)\end{array}$ & $\begin{array}{c}-0.0292^{* * *} \\
(0.0065)\end{array}$ \\
\hline Mean control at baseline & 0.187 & 0.0779 & 0.182 & 0.0693 \\
\hline$\%$ effect & 16.31 & 16.30 & 12.31 & 42.14 \\
\hline Sample size & 21,480 & 21,480 & 23,866 & 23,867 \\
\hline
\end{tabular}

Notes: Significance: ${ }^{* * *}: 1 \% ;^{* *}: 5 \% ;^{*}: 10 \%$. Standard errors clustered by municipality. Regressions control for a set of individual, household and municipality characteristics. In columns 1 and 2, estimating sample excludes the early treatment municipalities that received the payment before to the baseline survey was conducted. Only short run effects are presented. In columns 3 and 4 the estimating sample excludes the converted municipalities control municipalities that became treatment municipalities before the second follow-up survey was conducted. Only medium run effects are presented. 
Table A4: Comparison of characteristics across matched and unmatched samples

\begin{tabular}{|c|c|c|c|c|c|c|}
\hline & \multicolumn{3}{|c|}{ Panel A: Unmatched sample } & \multicolumn{3}{|c|}{ Panel B: Matched sample } \\
\hline & Treated & Control & $\mathrm{p}$-value difference & Treated & Control & $\mathrm{p}$-value difference \\
\hline \multicolumn{7}{|l|}{ Health insurance of the head } \\
\hline Private & 0.031 & 0.048 & 0.000 & 0.031 & 0.03 & 0.725 \\
\hline Subsidized & 0.646 & 0.688 & 0.000 & 0.646 & 0.659 & 0.131 \\
\hline Informally subsidized & 0.209 & 0.135 & 0.000 & 0.208 & 0.194 & 0.041 \\
\hline Age of head & 42.808 & 43.362 & 0.023 & 42.813 & 42.904 & 0.676 \\
\hline Age of spouse & 37.556 & 38.211 & 0.003 & 37.56 & 37.671 & 0.571 \\
\hline \multicolumn{7}{|l|}{ Education level head: } \\
\hline No education & 0.237 & 0.243 & 0.505 & 0.237 & 0.245 & 0.333 \\
\hline Incomplete primary & 0.151 & 0.144 & 0.275 & 0.151 & 0.145 & 0.304 \\
\hline Complete primary & 0.441 & 0.432 & 0.343 & 0.441 & 0.441 & 0.975 \\
\hline Incomplete secondary & 0.033 & 0.033 & 0.932 & 0.033 & 0.032 & 0.746 \\
\hline \multicolumn{7}{|l|}{ Education level spouse: } \\
\hline No education & 0.196 & 0.205 & 0.277 & 0.196 & 0.204 & 0.254 \\
\hline Incomplete primary & 0.16 & 0.16 & 0.959 & 0.16 & 0.16 & 0.976 \\
\hline Complete primary & 0.463 & 0.425 & 0.000 & 0.463 & 0.458 & 0.603 \\
\hline Incomplete secondary & 0.039 & 0.034 & 0.258 & 0.038 & 0.036 & 0.459 \\
\hline \multicolumn{7}{|l|}{ House walls } \\
\hline Good quality wood or bricks & 0.411 & 0.459 & 0.000 & 0.411 & 0.417 & 0.528 \\
\hline Adobe and poor quality wood & 0.534 & 0.5 & 0.001 & 0.534 & 0.536 & 0.879 \\
\hline Cardboard/vegetation/none & 0.054 & 0.041 & 0.003 & 0.054 & 0.047 & 0.088 \\
\hline Has piped gas & 0.065 & 0.074 & 0.074 & 0.065 & 0.063 & 0.63 \\
\hline Has piped water & 0.571 & 0.618 & 0.000 & 0.571 & 0.572 & 0.9 \\
\hline Has sewage system & 0.211 & 0.241 & 0.000 & 0.211 & 0.212 & 0.884 \\
\hline Has rubbish collection & 0.245 & 0.335 & 0.000 & 0.245 & 0.242 & 0.667 \\
\hline Has telephone & 0.066 & 0.086 & 0.000 & 0.066 & 0.067 & 0.835 \\
\hline Improved sanitation & 0.483 & 0.521 & 0.000 & 0.483 & 0.486 & 0.745 \\
\hline Own house & 0.645 & 0.639 & 0.568 & 0.644 & 0.636 & 0.321 \\
\hline Mean absolute bias & & 6.3 & & & 1.2 & \\
\hline Median absolute bias & & 6.1 & & & 0.8 & \\
\hline Pseudo $R^{2}$ & & 0.018 & & & 0.001 & \\
\hline
\end{tabular}

Notes:

The absolute standarized bias is taken over all regressors. Pseudo $R^{2}$ of probit model for the selection of treated households. 


\section{Table A5: First Stage Propensity Score. Dependent}

Variable: Treatment

\begin{tabular}{|c|c|c|c|c|}
\hline & \multicolumn{2}{|c|}{ First follow up } & \multicolumn{2}{|c|}{ Second follow up } \\
\hline & (1) & $(2)$ & $(3)$ & $(4)$ \\
\hline \multicolumn{5}{|l|}{ Health insurance of the head } \\
\hline Private & $-0.0570^{* *}$ & $(0.0267)$ & $-0.0532^{*}$ & $(0.0289)$ \\
\hline Public & $0.0316^{* *}$ & $(0.0139)$ & 0.0204 & $(0.0151)$ \\
\hline Informally subsidized & $0.1337^{* * *}$ & $(0.0152)$ & $0.1302^{* * *}$ & $(0.0165)$ \\
\hline Age of head & 0.0007 & $(0.0006)$ & 0.0000 & $(0.0007)$ \\
\hline Age of spouse & $-0.0014^{* *}$ & $(0.0007)$ & -0.0006 & $(0.0007)$ \\
\hline \multicolumn{5}{|l|}{ Education level of head } \\
\hline No education & $-0.0298^{*}$ & $(0.0168)$ & -0.0212 & $(0.0181)$ \\
\hline Incomplete primary & 0.0111 & $(0.0174)$ & 0.0034 & $(0.0187)$ \\
\hline Complete primary & -0.0077 & $(0.0151)$ & -0.0166 & $(0.0163)$ \\
\hline Incomplete Secondary & 0.0065 & $(0.0280)$ & 0.0101 & $(0.0301)$ \\
\hline \multicolumn{5}{|c|}{ Education level of spouse of head } \\
\hline No education & $0.0347^{* *}$ & $(0.0165)$ & $0.0383^{* *}$ & $(0.0178)$ \\
\hline Incomplete primary & $0.0375^{* *}$ & $(0.0163)$ & $0.0522^{* * *}$ & $(0.0174)$ \\
\hline Complete primary & $0.0604^{* * *}$ & $(0.0143)$ & $0.0654^{* * *}$ & $(0.0155)$ \\
\hline Incomplete Secondary & $0.0738^{* * *}$ & $(0.0253)$ & $0.0937^{* * *}$ & $(0.0263)$ \\
\hline \multicolumn{5}{|l|}{ House walls } \\
\hline Good quality wood or bricks & -0.2256 & $(0.1802)$ & -0.1526 & $(0.1970)$ \\
\hline Adobe and poor-quality wood & -0.2105 & $(0.1768)$ & -0.1382 & $(0.1943)$ \\
\hline Cardboard/vegetation/none & -0.1622 & $(0.1887)$ & -0.0904 & $(0.2055)$ \\
\hline Has piped gas & 0.0206 & $(0.0183)$ & 0.0149 & $(0.0198)$ \\
\hline Has piped water & -0.0083 & $(0.0104)$ & -0.0113 & $(0.0112)$ \\
\hline Has sewage system & $0.0502^{* * *}$ & $(0.0144)$ & $0.0571^{* * *}$ & $(0.0154)$ \\
\hline Has rubbish collection & $-0.1297^{* * *}$ & $(0.0137)$ & $-0.1224^{* * *}$ & $(0.0146)$ \\
\hline Has telephone & -0.0028 & $(0.0172)$ & -0.0291 & $(0.0192)$ \\
\hline Improved sanitation & -0.0025 & $(0.0107)$ & -0.0031 & $(0.0115)$ \\
\hline Own house & $0.0221^{* *}$ & $(0.0097)$ & 0.0137 & $(0.0104)$ \\
\hline Sample size & 12 , & & & \\
\hline
\end{tabular}

Notes: Marginal effects from probit estimation on program eligibility. Standard errors in parentheses in columns (2) and (4). Significance: ${ }^{* * *}: 1 \% ;^{* *}: 5 \% ;^{*}$ : $10 \%$. 


\section{Table A6: Difference in Difference Results Using Propensity Score Matching}

\begin{tabular}{|c|c|c|c|c|}
\hline & \multicolumn{2}{|c|}{ First follow up } & \multicolumn{2}{|c|}{ Second follow up } \\
\hline & $\begin{array}{l}\text { Reporting ill } \\
(1)\end{array}$ & $\begin{array}{c}\text { Reporting hospitalization } \\
(2)\end{array}$ & $\begin{array}{c}\text { Reporting ill } \\
(3)\end{array}$ & $\begin{array}{c}\text { Reporting hospitalization } \\
(4)\end{array}$ \\
\hline \multicolumn{5}{|l|}{ All adults } \\
\hline Program & $\begin{array}{l}-0.0150 \\
(0.0102)\end{array}$ & $\begin{array}{r}-0.0111^{*} \\
(0.0068)\end{array}$ & $\begin{array}{c}-0.0273^{* * *} \\
(0.0105)\end{array}$ & $\begin{array}{c}-0.0204^{* * *} \\
(0.0074)\end{array}$ \\
\hline Sample size on support & 12,375 & 12,375 & 10,545 & 10545 \\
\hline \multicolumn{5}{|l|}{ Women } \\
\hline Program & $\begin{array}{c}-0.0278^{* *} \\
(0.0139)\end{array}$ & $\begin{array}{r}-0.0201^{*} \\
(0.0114)\end{array}$ & $\begin{array}{c}-0.017 \\
(0.0164)\end{array}$ & $\begin{array}{l}-0.0151 \\
(0.0115)\end{array}$ \\
\hline Sample size on support & 6,116 & 6,116 & 5,325 & 5,325 \\
\hline \multicolumn{5}{|l|}{ Men } \\
\hline Program & $\begin{array}{l}-0.0015 \\
(0.0156)\end{array}$ & $\begin{array}{l}-0.0025 \\
(0.0072)\end{array}$ & $\begin{array}{c}-0.0380^{* * *} \\
(0.0136)\end{array}$ & $\begin{array}{c}-0.0260^{* * *} \\
(0.0087)\end{array}$ \\
\hline Sample size on support & 6,261 & 6,261 & 5,220 & 5,220 \\
\hline \multicolumn{5}{|c|}{ Titulars and non-titulars in treatment households } \\
\hline Within household program & $\begin{array}{c}0.0150 \\
(0.0236)\end{array}$ & $\begin{array}{l}0.0268 \\
(0.0167)\end{array}$ & $\begin{array}{c}0.0116 \\
(0.0249)\end{array}$ & $\begin{array}{c}0.024 \\
(0.0212)\end{array}$ \\
\hline Sample size on support & 3,484 & 3,484 & 3,080 & 3,080 \\
\hline \multicolumn{5}{|c|}{ Non-Titulars in treatment and all women in control households } \\
\hline Program & $\begin{array}{l}-0.0277 \\
(0.0207)\end{array}$ & $\begin{array}{l}-0.017 \\
(0.0136)\end{array}$ & $\begin{array}{l}-0.0305 \\
(0.0208)\end{array}$ & $\begin{array}{c}-0.0284^{* *} \\
(0.0142)\end{array}$ \\
\hline Sample size on support & 3,447 & 3,447 & 2,945 & 2,945 \\
\hline
\end{tabular}

Notes: Bootstrapped Standard Errors. Significance: ${ }^{* * *}: 1 \% ;^{* *}: 5 \% ;^{*}: 10 \%$. Matching using a non-parametric kernel method. Control variables to estimate the propensity score are presented in Table A4 and first stage estimation results are presented in Table A5. 


\section{Table A7: Program Effect on Mortality}

Whether any adult household member died Total number of adult household members dying in the reference period in the reference period

(1)
(3)

\begin{tabular}{lcccc}
\hline Program & $\begin{array}{c}-0111^{* *} \\
(0.0047)\end{array}$ & $\begin{array}{c}-0.0071 \\
(0.0070)\end{array}$ & $\begin{array}{c}-0.0178^{* * *} \\
(0.0067)\end{array}$ & $\begin{array}{c}-0.0130 \\
(0.0096)\end{array}$ \\
\hline Sample size & 6,800 & 6,128 & 6,800 & 6,128 \\
\hline
\end{tabular}

Notes: Marginal effects from Probit regressions presented in column 1 and 2. Regressions control for Treatment and Year and a set of individual, household and municipality characteristics. The reference period for the first follow-up is defined by the time between the baseline survey and the first follow up. The reference period for the second follow-up is defined by the time between the first and the second follow up. Significance: *** : $1 \% ;^{* *}: 5 \% ;^{*}: 10 \%$. Standard errors clustered by municipality. 


\section{Table A8: Placebo Regressions: Program Effect on Adult's Education}

Knows how to read Knows how to write Level of education

(1)

(2)

Panel A: First follow up

$\begin{array}{lccc}\text { Program } & 0.0097 & 0.0089 & 0.0066 \\ & (0.0117) & (0.0121) & (0.0080) \\ \text { Sample size } & 29,683 & 29,683 & 28,804 \\ & & & \\ \text { Panel B: Second follow up } & & 0.0187 \\ \text { Program } & 0.0122 & 0.0122 & (0.0126) \\ & (0.0097) & (0.0099) & 25,175 \\ \text { Sample size } & 25,789 & 25,789 & \end{array}$

Notes: Marginal effects from Probit regressions presented in columns 1 and 2 . In column 3 we present the results from an OLS regression where the level of education takes one of the following values: No education $(=1)$; Pre-school $(=2)$;

Incomplete Primary (=3); Complete Primary $(=4)$; Incomplete Secondary $(=5)$; Complete Secondary (=6); Technical Education $(=7)$; University, not-graduated $(=8)$; University, graduated $(=9)$; Post-graduate $(=10)$. Regressions control for Treatment $_{c}$ and Year $_{t}$ and a set of individual, household and municipality characteristics. Sample restricted to individuals who are in observed in both rounds of the survey. Significance: ${ }^{* *}: 1 \% ;^{* *}: 5 \% ;^{*}: 10 \%$. Standard errors clustered by municipality. 


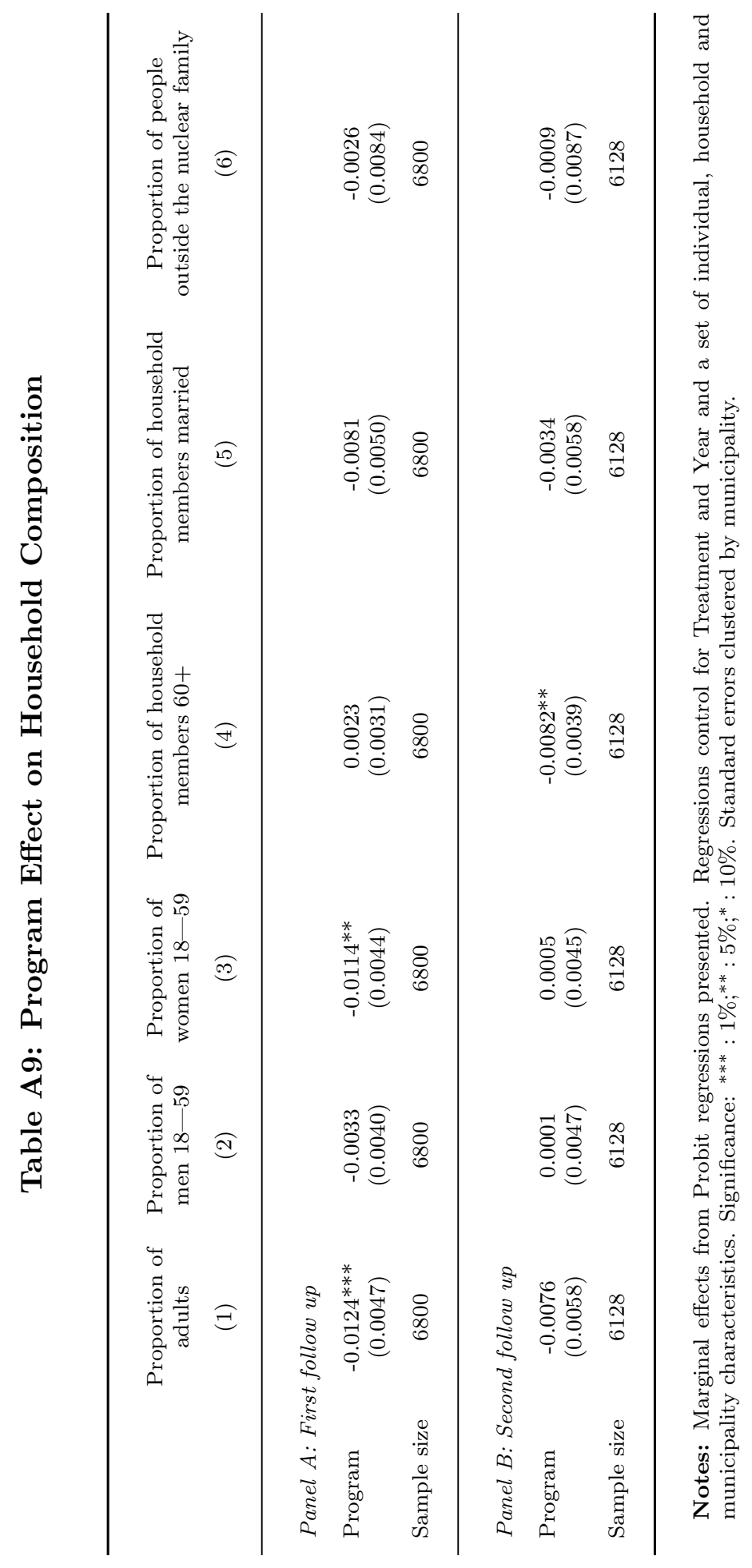




\section{University Library}

\section{- M M I N E R VA A gateway to Melbourne's research publications}

Minerva Access is the Institutional Repository of The University of Melbourne

Author/s:

Contreras Suarez, D;Maitra, P

Title:

Health spillover effects of a conditional cash transfer program

Date:

2021

Citation:

Contreras Suarez, D. \& Maitra, P. (2021). Health spillover effects of a conditional cash transfer program. Journal of Population Economics, 34 (3), pp.893-928. https:// doi.org/10.1007/s00148-020-00809-y.

Persistent Link:

http://hdl.handle.net/11343/258654 